Maestría en Economía

Facultad de Ciencias Económicas

Universidad Nacional de La Plata

$\underline{\text { Tesis }}$

\title{
Incidencia de los Subsidios a los Servicios Públicos en Argentina: el sistema vigente en 2015 y posibles escenarios de reforma. ${ }^{1}$
}

Julio, 2016

Alumno: Lic. Leandro Salinardi

Director: Mg. Jorge Pablo Puig

Co-Director: Dr. Leonardo Gasparini

\footnotetext{
1 El presente trabajo corresponde a mi tesis de Maestría en Economía de la Facultad de Ciencias Económicas de la Universidad Nacional de La Plata. Agradezco muy especialmente a mi gran amigo y director (en ese orden) Jorge Pablo Puig, por su infinita paciencia y profesionalidad, quien me mostró el mejor camino a seguir en este proceso. También, a Leonardo Gasparini, cuyos sabios consejos fueron determinantes en la concreción de este proyecto. Quiero agradecerles también a Fernando Navajas y a Mariana Marchionni por sus valiosos comentarios y aportes. Por último, quiero agradecerle a Facundo Crosta quien confió en mí desde el primer momento y me facilitó el espacio para concentrarme en este proyecto. Los errores y omisiones son de mi exclusiva responsabilidad.
}

Dedico esta tesis con mucho cariño a mis padres, Susana y Vicente, quienes me mostraron el camino recto que los buenos hombres siguen. 


\section{Introducción}

Durante los últimos años Argentina ha sostenido una activa política de subsidios a los servicios públicos. Tras la crisis del año 2001, las tarifas de éstos fueron congeladas en un intento de compensar los efectos negativos sobre el poder adquisitivo de los hogares. Sin embargo, estos subsidios aumentaron de manera constante desde el año 2006, convirtiéndose en uno de los rubros más importantes en el conjunto de gastos del gobierno nacional. El Gráfico 1 muestra la evolución de los subsidios ${ }^{2}$ a los servicios públicos y se observa que en términos reales y desde el año 2006, los subsidios a la electricidad, gas (de red y envasado), transporte y agua se vieron incrementados en un $500 \%$, pasando a representar más del $4 \%$ del Producto Bruto Interno de Argentina (más del $80 \%$ concentrado en el sector energético). En el año 2015, los mismos ascendieron a más de 200.000 millones de pesos ${ }^{3}$.

Gráfico 1. Evolución del gasto en subsidios a los servicios públicos en argentina. En términos reales y como porcentaje del PBI.

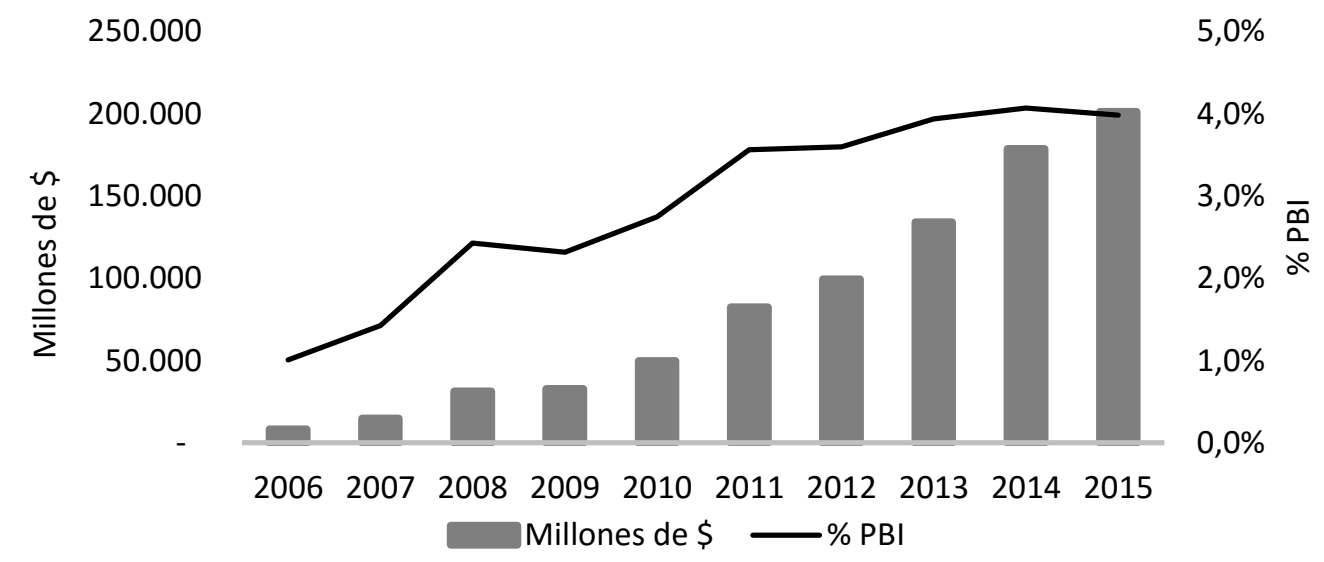

Fuente: elaboración propia en base a datos de Instituto Nacional de Estadísticas y Censos (INDEC) y Asociación Argentina de Presupuesto y Administración Pública (ASAP).

No existen dudas, desde una perspectiva distributiva, que los subsidios pueden ser una poderosa herramienta para proteger a los sectores más vulnerables de una población. Sin embargo, en Argentina se ha presentado un importante problema de focalización, debido a que gran parte de las transferencias corrientes han sido absorbidas por las clases superiores y los consumidores no residenciales ${ }^{4}$.

En los últimos meses el gobierno nacional encaró un proceso de reforma de los subsidios a los servicios públicos, teniendo en cuenta el problema de focalización descrito precedentemente. Sin

\footnotetext{
${ }^{2}$ A lo largo del presente trabajo, se referirá a "subsidios" como aquellas transferencias corrientes que el Estado Nacional realiza/ó a los sectores eléctricos, gas, agua y saneamiento y transporte.

${ }^{3}$ Informe de Ejecución del Gasto, Asociación Argentina de Presupuesto y Administración Pública (ASAP), 2016.

${ }^{4}$ Castro y Barafani, 2015; Lombardi et al, 2014; Marchionni et al, 2008; Navajas, 2015; Navajas (ed.), 2008; Puig y

Salinardi, 2015.
} 
embargo, aún los resultados en materia distributiva no son del todo claros. Dado este inconveniente y la necesidad de realizar correcciones al diseño de la política de subsidios a los servicios públicos en Argentina, el presente estudio pretende realizar un diagnóstico del sistema vigente en 2015 con particular foco en su incidencia distributiva, utilizando la Encuesta Nacional de Gasto de los Hogares ${ }^{5}$ 2012-2013 (ENGHo) e información administrativa específica de cada sector analizado, para luego ensayar una gama de escenarios de reforma de los mismos que permitan mejorar la focalización de éste tipo de políticas, con el objetivo de alcanzar una mejora en la distribución del ingreso.

En lo que sigue, el trabajo se estructura de la siguiente manera: a continuación se realiza una descripción del sistema de subsidios a los servicios públicos vigente en el año 2015, en particular a la electricidad, gas de red, gas envasado, transporte en colectivo y tren, agua y saneamiento, y se realiza un análisis de incidencia distributiva de los mismos. Posteriormente, se diseñan una serie de escenarios de reforma en pos de una mejora en la focalización de los mismos (en el caso de que el resultado de incidencia sea pro-rico) y su incidencia distributiva global; y finalmente se expone las conclusiones de los ejercicios llevados a cabo.

\section{Descripción del sistema de subsidios al consumo de servicios públicos y su incidencia distributiva: un análisis ex ante}

\section{II.1. Energía eléctrica residencial}

\section{II.1.1. Breve descripción del sector}

El sector eléctrico en Argentina funciona bajo la configuración del Mercado Eléctrico Mayorista (MEM), en el cual se intercambian las cantidades de energía eléctrica al por mayor. Los principales agentes que intervienen en dicho mercado son las empresas de generación (que ofrecen energía eléctrica) y las empresas de distribución de electricidad (quienes constituyen la demanda del mercado). La empresa encargada de administrar el funcionamiento del mercado, propiedad del Estado Nacional con representación minoritaria y de los agentes del MEM a través de asociaciones civiles que los representan agrupados en asociaciones de Generadores, de Transportistas, de Distribuidores y de Grandes Consumidores, es la Compañía Administradora del Mercado Mayorista Eléctrico Sociedad Anónima (CAMMESA).

En un principio, le intención de la implementación del MEM era fortalecer los mecanismos de mercado, tratando de buscar la emisión de señales de eficiencia que guiaran los incentivos de los agentes económicos, y así lograr un mejor desarrollo del sector eléctrico. La cotización horaria de la energía (precio spot) responde al costo marginal de producción en el momento de la generación, lo que permite a la demanda, compuesta por grandes usuarios industriales y empresas distribuidoras, recibir señales eficientes de costo de generación eléctrica (Campoy, 2015).

Sin embargo, la evolución hacia el alza de los costos de generación producto del incremento del precio de los hidrocarburos, junto con la decisión política de mantener inalterada la tarifa eléctrica

\footnotetext{
${ }^{5}$ Véase el anexo a este trabajo para una descripción detallada de dicha encuesta.
} 
al consumo residencial, generó un sistemático desfasaje entre el precio que pagaban las distribuidoras por la energía (precio de la demanda) y el costo de generación, que no es otra cosa que el costo promedio horario mensual de la energía que declaran los generadores de energía (o precio monómico). Este último es calculado por CAMMESA y publicado en su sitio web. La diferencia entre el precio monómico y el precio que paga la demanda (distribuidoras) es el subsidio al servicio público que, multiplicado por la cantidad reportada de demanda por sector, arroja el monto total de subsidios que el Estado Nacional asigna a CAMMESA (Campoy, 2015; Lombardi et al, 2004).

En el año 2015, el precio monómico fue de $667 \$ / M W h$ mientras que el precio que enfrentaba la demanda (distribuidoras) fue de 31 \$/MWh. A su vez, la cantidad de energía eléctrica residencial demandada y reportada por la Asociación de Distribuidores de Energía Eléctrica de la República Argentina (ADEERA), ascendió a 55.453.430 MW. Los datos administrativos disponibles en cuanto al monto total de subsidios al sector eléctrico, no diferencia entre consumo residencial y no residencial. Por lo tanto, para obtener el monto del total de subsidio que se asignó a la demanda residencial, de particular interés en el presente trabajo, se multiplica la diferencia entre el precio monómico (oferta) y el precio de demanda (distribuidoras) por el total de $\mathrm{MW}$ demandados por el sector pertinente. De esta manera, se obtuvo que el monto en pesos de subsidios a la energía eléctrica residencial ascendió a \$35.268MM en el año 2015.

Por su parte, CAMMESA recibió del gobierno nacional en el año 2015 casi $\$ 90.000 M M$ : el monto de subsidios al grupo de hogares representa un $46 \%$ del total de transferencias corrientes efectuadas a la firma. La Tabla 1 a continuación, ilustra lo recientemente explicado:

Tabla 1. Transferencias a CAMMESA, Dda. Residencial, Precios y Subsidios.

\begin{tabular}{|c|c|c|}
\hline \multicolumn{3}{|c|}{ Año 2015 } \\
\hline Demanda Residencial & 55.453 .430 & $\mathrm{MWh}$ \\
\hline Precio de Oferta (Monómico) & 667 & \$/MWh \\
\hline Precio de Demanda & 31 & \$/MWh \\
\hline Subsidios & 35.268 & Millones \$ \\
\hline Transferencias totales a CAMMESA & 89.793 & Millones \$ \\
\hline
\end{tabular}

Fuente: elaboración propia en base a datos de ADEERA, ASAP y CAMMESA ${ }^{6}$

\section{II.1.2. Incidencia distributiva}

Para computar la incidencia distributiva del subsidio antes descripto, el estudio se basa en microdatos desagregados a nivel de hogares sobre acceso, consumo y gasto en electricidad. Los mismos provienen de la ENGHo.

\footnotetext{
${ }^{6}$ El informe anual de CAMMESA sólo publica el precio promedio de los consumidores residenciales, comerciales e industriales, que es de ARS 100/MWh. El sector residencial enfrenta un precio de demanda de aproximadamente 31\$/MWh. Agradezco a Fernando Navajas por compartir sus estimaciones de los precios residenciales en base a datos administrativos de CAMMESA y el MEM.
} 
A partir de aquí, se pone particular atención en el gasto en el servicio de electricidad y su participación en el gasto total de los hogares dado que el subsidio se asignará en función de esta variable.

Si bien existe una variable en la mencionada encuesta que reporta el consumo de los hogares del servicio de particular interés, ésta muestra considerables problemas de representatividad desde varios puntos de vista. Afortunadamente se pueden observar los gastos, y así inferir el consumo ${ }^{7}$. Esto último es posible gracias a que se dispone de información fidedigna acerca de los precios a los cuales se realizaron dichos gastos, es decir, a través de la utilización de los cuadros tarifarios ${ }^{8}$ correspondientes de cada compañía distribuidora.

Siguiendo a Navajas (ed.) (2008) y Marchionni et al. (2008), y a los fines de recuperar el consumo implícito en los gastos reportados por los hogares, se invierte la fórmula tarifaria

$$
T^{h}=A+B * C^{h}
$$

Donde $T^{h}$ es la tarifa, $\boldsymbol{A}$ y $\boldsymbol{B}$ reportan a la tarifa en dos partes (cargos fijo y variable respectivamente) , y $C^{h}$ el consumo físico del hogar $\boldsymbol{h}^{10}$. Es importante destacar que se consideran las diferencias entre las distintas regiones de Argentina, tanto en los parámetros tarifarios como en el tratamiento impositivo ${ }^{11}$.

Para llevar a cabo el ejercicio de incidencia distributiva del subsidio a la electricidad residencial (y para el resto de los ejercicios desarrollados en el presente trabajo), en primer lugar, es necesario ordenar a la población por algún indicador de bienestar ${ }^{12}$. Para tal fin, se utiliza el ingreso per cápita familiar (IPCF), y se los ordena en quintiles de ingreso ${ }^{13} 14$.

Posteriormente, se toma la distribución de cantidades consumidas calculadas como se detalló anteriormente a partir de la ENGHo. Luego, utilizando los cuadros tarifarios disponibles por región, se calculan los montos que cada hogar debe pagar con y sin subsidio, y luego se extrae el monto del subsidio por diferencia. Por último, se computa el subsidio en base a la distribución del consumo y se analiza el mismo en términos de su incidencia absoluta, es decir, que proporción es apropiado por cada quintil de la distribución. Así, un subsidio será pro-rico si se concentra en la parte más alta de la distribución del ingreso, mientras que será pro-pobre si lo hace en los quintiles más pobres de la misma.

\footnotetext{
${ }^{7}$ El método de recupero de cantidades a partir de los gastos de los hogares fue usado por primera vez en Navajas (ed.) (2008) y chequeada su robustez en Navajas (2007).

8 Véase el Cuadro A1 en Anexo para un detalle geográfico de los cuadros tarifarios utilizados.

${ }^{9}$ Véase Cuadro A3 en Anexo para un detalle sobre la configuración de la tarifa de usuarios residenciales.

${ }^{10}$ Véase Cuadro A2 en Anexo para una detallada descripción de la estimación del consumo físico a partir de la ENGHo.

${ }^{11}$ A este respecto, se sigue a Cont (2008) quien arroja un detalle sobre la configuración impositiva regional

12 Para una discusión detallada al respecto, véase Gasparini (1998) y Fernández Felices et al. (2014).

13 Para una discusión acerca de los problemas que presenta la utilización de la variable ingreso en cuanto a la subdeclaración y volatilidad de la misma, ver Gasparini, Cicowiez y Sosa Escudero (2012).

${ }^{14}$ Una opción igualmente válida sería la utilización del consumo per cápita familiar como indicador de bienestar. Puig y Salinardi (2015) la utilizan en su trabajo y sus resultados no se ven significativamente alterados.
} 
En el Gráfico 2, se puede observar la participación de cada quintil poblacional en los subsidios. Se aprecia que el subsidio a la electricidad resulta pro-rico: es decir que no se concentran las transferencias corrientes en los quintiles más bajos de la distribución del ingreso, sino que lo hacen de manera pro-rica a lo largo de la misma. Estos resultados son similares a los encontrados por Lombardi et al. (2014), Puig y Salinardi (2015), Castro y Barafini (2015) y recientemente en el trabajo de Hancevic, Cont y Navajas (2016), quienes realizan un análisis similar para el AMBA.

Gráfico 2. Distribución de los subsidios a la electricidad.

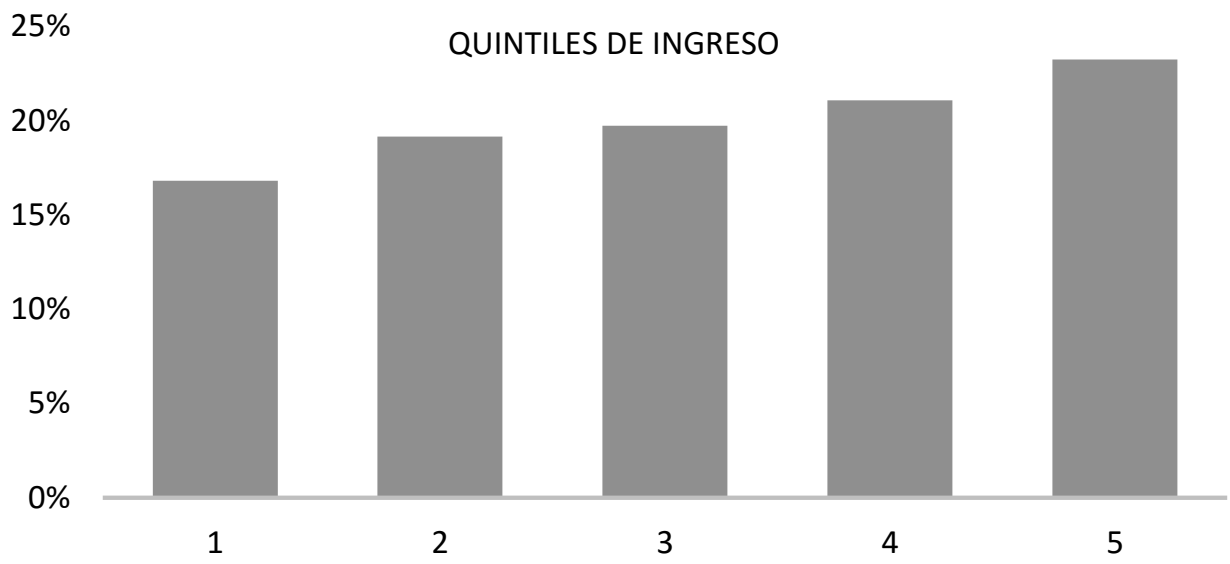

Fuente: elaboración propia.

\section{II.2. Gas de red y envasado}

\section{II.2.1. Breve descripción del sector ${ }^{15}$}

\section{Gas de red}

En Argentina, luego de su extracción, el gas de red es transportado vía dos grandes empresas: Transportadora de Gas del Norte S.A. y Transportadora de Gas del Sur S.A. que se reparten el territorio en dos, estableciéndose la división a la altura de los límites superiores de las provincias de Buenos Aires, La Pampa y Neuquén. Dichas empresas transportan el gas hasta las 9 empresas licenciatarias del servicio de distribución que se reparten el territorio nacional según su zona de influencia.

Los subsidios al gas se asignan a través de tres fideicomisos regulados por el Ente Nacional Regulador del Gas (ENARGAS), destinados a la importación de gas, al consumo residencial, y al consumo de gas envasado. El subsidio a las importaciones de gas se asigna a través de un fideicomiso encargado de financiar la compra de gas importado para satisfacer las necesidades nacionales del mismo. La diferencia entre el costo de la importación pagado por ENARSA y el precio pagado por las empresas

\footnotetext{
15 Ver en Anexo Tabla A1 los montos de subsidios transferidos en los últimos años para cada concepto.
} 
se financia con fondos del Tesoro Nacional. Si bien una parte de ese costo es afrontado por los consumidores a través de un cargo por costo del gas importado, la gran mayoría del mismo es cubierto por el Estado Nacional.

El subsidio al consumo residencial en la región patagónica y el Departamento de Malargüe es asignado a través de un fideicomiso creado por el artículo 75 de la Ley 25.565. El mismo se constituye con un recargo sobre el precio del gas natural en punto de ingreso al sistema de transporte y se aplica a la totalidad de los metros cúbicos que se consumen y/o comercializan por redes o ductos. Los productores de gas actúan como agentes de percepción en oportunidad de producirse la emisión de la factura (Lombardi et al. 2014).

\section{Gas Envasado (Programa Hogar)}

El subsidio al gas envasado se realiza a través de un programa de transferencias llamado "Programa HOGAR" y que consiste en asignar una transferencia monetaria por garrafa consumida a todos los usuarios de bajos recursos que residan en zonas sin el servicio de gas natural por redes o que no se encuentren conectados a la red de distribución domiciliaria de gas. Para acceder al mismo, existen ciertos requisitos que deben cumplir los beneficiarios del programa como percibir hasta dos salarios mínimos, y hasta tres salarios mínimos cuando en el hogar resida un familiar discapacitado o se trate de viviendas de uso social y comunitario.

En cuanto a la cantidad de garrafas que se subsidian por hogar, la misma varía en función de la cantidad de miembros del hogar, la ubicación geográfica y la época del año ${ }^{16}$. El monto a depositar correspondiente al subsidio por dos garrafas por hogar, alcanza los 154 pesos (77 por cada una de 10 kilogramos).

\section{II.2.2. Incidencia distributiva}

\section{Gas de red}

A la hora de obtener los consumos del servicio de gas de red, se adopta un criterio similar al utilizado a la hora de realizar el estudio para energía eléctrica.

Para el caso de subsidios a la electricidad, se implementó un sistema de cálculo del consumo a partir del gasto reportado en el servicio por hogar, dadas las inconsistencias y problemas de medición que presentaba la variable de cantidad reportada en la Encuesta. Para el caso del gas de red, se intenta recuperar de la misma manera las cantidades consumidas a partir del gasto reportado en la ENGHo, dado que la variable que reporta consumo del servicio presenta los mismos inconvenientes que el

\footnotetext{
${ }^{16} \mathrm{~A}$. Se establece una cantidad adicional para aquellos beneficiarios que residan en las provincias de: Tierra del Fuego, Santa Cruz, Chubut, Río Negro y Neuquén.

B. Se establece una cantidad adicional para aquellos beneficiarios cuyos hogares cuenten con más de cinco (5) integrantes. C. Se establece un calendario estacional (más subsidios para los meses de invierno).
} 
caso de la electricidad ${ }^{17}$. Para la aplicación de los conceptos tarifarios, la Resolución ENARGAS I409 determina 8 categorías de consumos para clientes residenciales en función de específicos rangos de consumo. Esta categorización se realiza considerando los consumos del período corriente más los 5 períodos inmediatos anteriores. De esta manera, se cuantifica el consumo por hogar en metros cúbicos. Una vez obtenidas las cantidades, se procede a calcular el subsidio por hogar utilizando los cuadros tarifarios de la Resolución ENARGAS 1409 por región ${ }^{18}$.

Una vez realizados los cálculos precedentes, se procede a realizar el análisis de incidencia distributiva, resumiéndose los resultados en el Gráfico 3. En este, se puede observar la participación de los subsidios, que permite comprobar si la distribución del mismo entre la población resulta propobre o pro-rica. Se deduce entonces que los subsidios al gas de red son pro-ricos: es decir que no se concentran las transferencias en los quintiles más bajos de la distribución del ingreso, sino que lo hacen de manera pro-rica a lo largo de la misma. Estos resultados presentan el mismo problema de focalización que los subsidios a la electricidad, en línea con el estudio previamente llevado a cabo. Sin embargo, se observa que el sesgo pro-rico es mayor en el estudio del gas de red. Esto se vincula con el hecho de que el gas de red no tiene el mismo grado de cobertura o acceso que la electricidad, con los hogares vulnerables más sesgados a proveerse del servicio vía gas envasado ${ }^{19}$.

Gráfico 3. Distribución de los subsidios al gas de red.

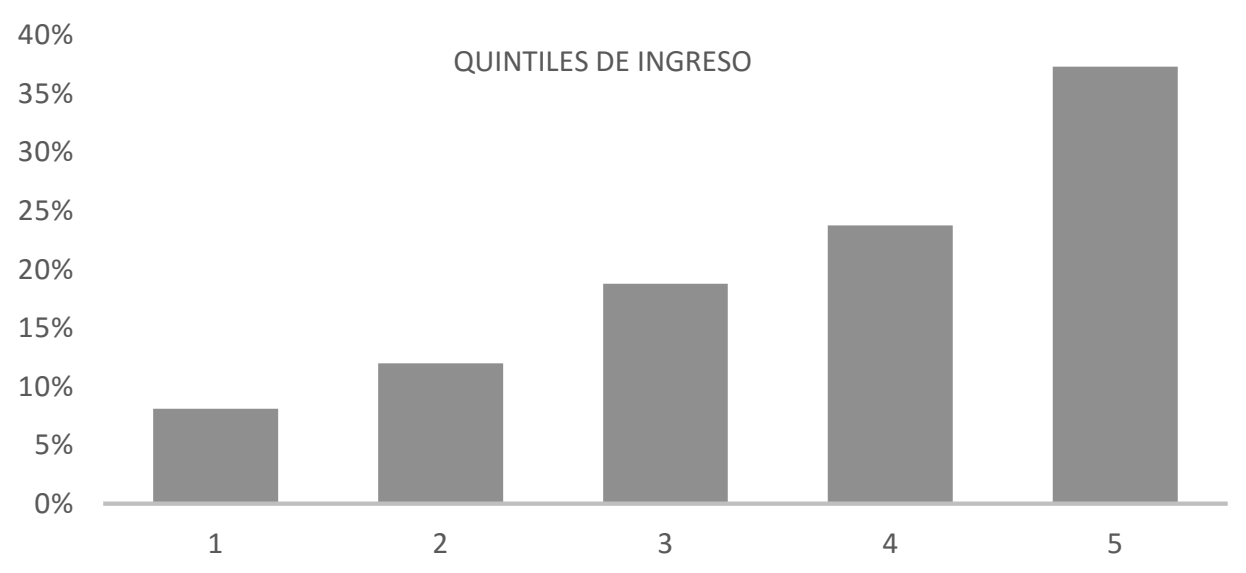

Fuente: elaboración propia.

\footnotetext{
17 Véase el Cuadro A5 en Anexo para un mayor detalle sobre la composición de la tarifa de gas.

18 Véase el Cuadro 6 en Anexo para mayor detalle al respecto del cálculo del subsidio al gas de red.

${ }^{19}$ Véase la descomposición del indicador $\Omega$ en Marchionni et al (2008) para comprender cómo la incidencia o el sesgo prorico puede depender del acceso.
} 


\section{Gas Envasado (Programa Hogar)}

Metodológicamente, a partir de la pregunta que se reporta en la ENGHo sobre si algún miembro del hogar adquirió gas envasado en los últimos dos meses ${ }^{20}$, se obtienen las cantidades y el monto en dicho ítem ${ }^{21}$. Luego, a las cantidades por hogar se las escala para obtener la cantidad de garrafas consumidas por el hogar. Dada dicha cantidad de garrafas consumidas, se le aplica el subsidio a aquellos hogares que figuran sin conexión a gas de red. El pertinente subsidio es de 77 pesos por garrafa (dado que es el monto que se le transfiere a cada hogar como se explicó precedentemente).

El Gráfico 4 muestra los resultados y se verifica luego del análisis de incidencia llevado a cabo, que el impacto del Programa HOGAR tiene un efecto pro-pobre en la distribución del ingreso de la población. Este es un resultado deseable que muestra una clara correcta focalización del subsidio en contraposición al resto de los subsidios a la energía.

Gráfico 4. Distribución de los subsidios al gas envasado.

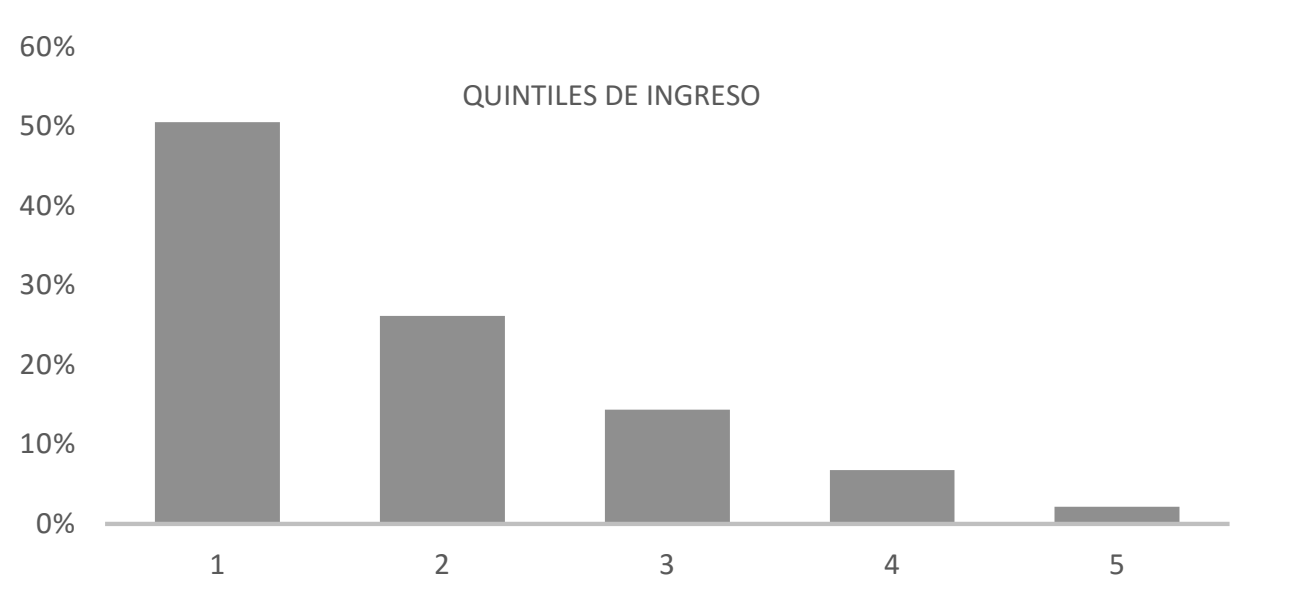

Fuente: elaboración propia.

\footnotetext{
20 La pregunta específica es: “¿En los últimos dos meses, usted o algún miembro del hogar adquirió servicios de gas, tales como gas envasado en garrafa?" (Medida en Kilogramos a través del código 342101). La ENGHo 2012/13 utilizada en el presente estudio, reporta que 3.923.811 de hogares utilizan el gas en garrafa.

${ }^{21}$ A modo de simplificar los cálculos, en este trabajo las cantidades se obtienen a partir de unidades de garrafa dado que el precio de referencia y el subsidio está calculado en función de ellas. Realizar el cálculo en m3 resulta una alternativa igualmente válida y además permitiría comparar de manera más efectiva las distribuciones de consumo de gas de los hogares conectados a la red respecto a los que usan garrafa, o comparar la estructura de gasto de hogares con similares características pero que sólo difieren en el uso de gas por redes o gas envasado.
} 


\section{II.2.3. Incidencia distributiva, agregada (gas de red y gas de garrafa).}

Finalmente, se realiza el ejercicio de incidencia total del gas, considerando tanto gas de red como gas envasado y los resultados se muestran en el Gráfico $5^{22}$. El resultado agregado de incidencia de los subsidios al gas, indica la pro-riqueza de este tipo de transferencias, denotando una vez más el problema de focalización ya explicado.

Gráfico 5. Distribución de los subsidios al gas (red y envasado).

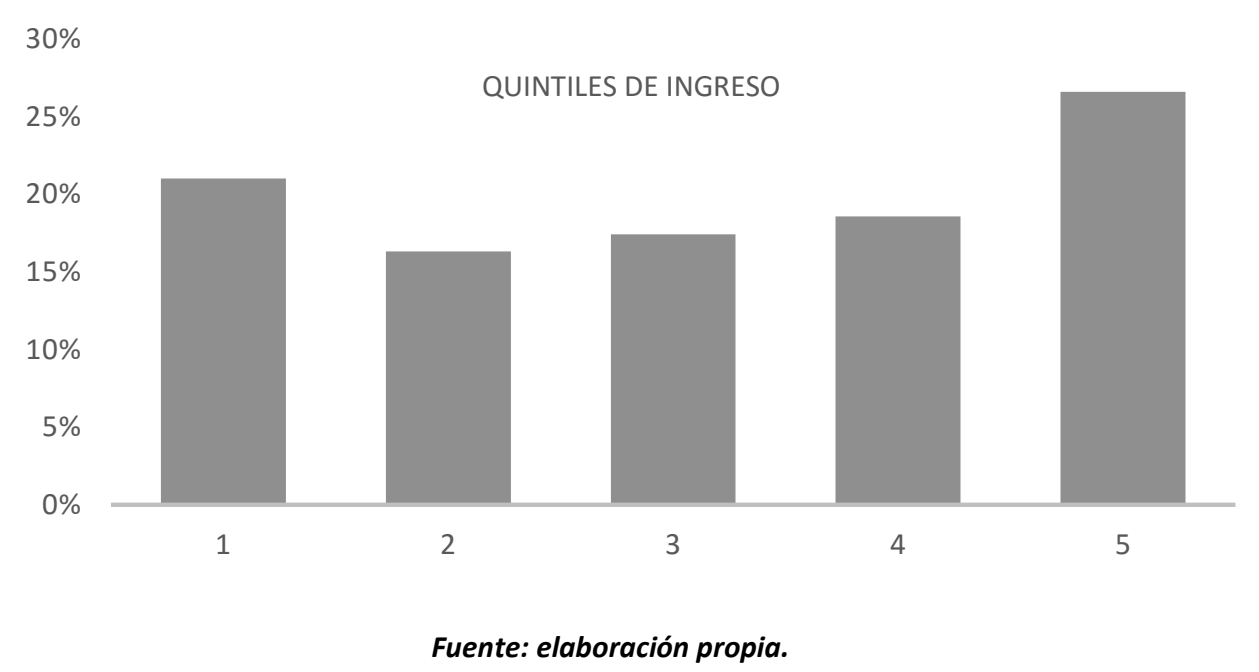

\section{II.3. Transporte ${ }^{23}$}

\section{II.3.1. Breve descripción del sector ${ }^{24}$}

Las transferencias al sector transporte (sistema automotor y ferroviario), según datos de la ASAP, fueron de cerca de 46.000 millones de pesos en el año 2015, representando una variación interanual del $30 \%$.

Los subsidios al transporte automotor se hacen efectivos a través del Fondo Fiduciario del Sistema de Infraestructura del Transporte, quien tiene a su cargo las compensaciones a colectivos y micros de media y larga distancia. Por su parte, aquellas transferencias corrientes al transporte ferroviario se realizan principalmente a través de dos empresas públicas: la Administradora de RRHH Ferroviarios y Operador Ferroviario S.E., y tienen como objetivo atender los gastos en personal de cinco de las siete líneas de ferrocarril, como así también las transferencias a las nuevas empresas concesionarias de las mismas cinco líneas. A su vez, se cuentan los subsidios destinados a dos

\footnotetext{
22 Si bien las cantidades de gas de red se miden en $\mathrm{m} 3$, mientras que las de gas envasado en cantidad de garrafas, el ejercicio se realiza ponderando por monto de subsidios lo que permite realizar una agregación consistente.

${ }^{23}$ Los subsidios analizados aquí corresponden a tren y colectivo.

${ }^{24}$ Ver en Anexo Tabla A1 los montos de subsidios transferidos en los últimos años para cada concepto.
} 
empresas privadas: Ferrovías y Metrovías, concesionarias de las otras dos líneas de ferrocarril (Belgrano Norte y Urquiza, respectivamente).

El actual sistema de subsidios al transporte público, especialmente en el Área Metropolitana de Buenos Aires (AMBA), es tal que todas las tarifas que pagan los usuarios de colectivo y tren principalmente, son subsidiados de alguna manera. En AMBA, la población tiene acceso a una tarjeta de sistema de transporte integrado ${ }^{25}$ (SUBE), que proporciona una tarifa subvencionada.

Además de eso, algunos individuos (potencialmente, los más vulnerables) tienen acceso a las "Tarifas Diferenciales SUBE", que les permiten pagar tarifas aún más bajas con un subsidio de $40 \%$. Seis grupos son actualmente elegibles para esta tarifa especial: jubilados, empleados domésticos, los receptores de la "Asignación Universal por Hijo", y los receptores del Programa "Jefes de Hogar", destinatarias del subsidio de embarazo y los veteranos de Malvinas.

\section{II.3.2. Incidencia distributiva}

En cuanto a la metodología utilizada para llevar a cabo el análisis para el servicio de transporte, es importante destacar que el ejercicio se concentra en la región de AMBA, que comprende la Ciudad Autónoma de Buenos Aires y los Partidos del Gran Buenos Aires. Esto se debe principalmente a que la mayoría de las transferencias corrientes al transporte se concentran en esta región, al igual que la mayor incidencia de la SUBE, mientras que en el resto del país su incidencia es menor al $1 \%$.

Específicamente, para evaluar la incidencia distributiva, se requiere conocer el perfil socioeconómico, el acceso al servicio de transporte de cada individuo que habita en AMBA, y su intensidad de uso medida en viajes y la tarifa que paga por cada uno de ellos. Para ello, se utilizan distintas fuentes que permiten cubrir estas demandas informativas y se conjugan microdatos a nivel individuo para identificar el perfil socioeconómico con indicadores promedio sobre uso para diversos tipos de usuarios del transporte en tren y colectivos.

A partir de la ENGHo, se obtienen las cantidades de viajes de cada medio de transporte que reportan los individuos para cada una de las categorías contempladas en el esquema tarifario. En este ejercicio, es importante destacar que las categorías de individuo que se contemplan para aquellos beneficiarios que reciben un subsidio específico para viajes el cual se canaliza vía la tarjeta SUBE en el formato de una tarifa social, son aquellos beneficiarios de la Asignación Universal por Hijo, Jubilados y Pensionados, Estudiantes, receptores del programa Progresar ${ }^{26}$, y personal del trabajo

\footnotetext{
${ }^{25}$ Sistema que facilita a cada usuario, a través de una tarjeta inteligente, abonar los viajes en colectivos, subtes y trenes adheridas a la "Red SUBE", tanto en el transporte público del Área Metropolitana de Buenos Aires (AMBA) como en las líneas de colectivos de las siguientes ciudades: Mar del Plata, Villa Gesell, Partido de La Costa, Pinamar, Bahía Blanca, Neuquén, Río Grande, Ushuaia, Formosa, Paraná y Santa Fe, entre otras.

26 Se presenta un inconveniente en el caso de los beneficiarios del programa Progresar, dado que no se indaga directamente en la encuesta, razón por la cual su participación se infiere a partir de los requisitos de acceso y las características de los ingresos que reciben.
} 
doméstico ${ }^{27}$. Posteriormente, una vez que se identifican los perfiles, se aplica el esquema tarifario para cada categoría ( $\mathrm{AUH}$, Jubilados, etc.). El subsidio surge de la diferencia entre una tarifa técnica ${ }^{28}$ del servicio y la tarifa que efectivamente abona cada individuo, según la categoría a la cual pertenece.

El Gráfico 6 muestra la incidencia distributiva de los subsidios al servicio de transporte en colectivo mientras que en el Gráfico 7 se exponen los resultados para los subsidios al transporte de tren. El análisis confirma que los subsidios tanto al transporte de colectivo como de tren presentan un comportamiento levemente pro-rico.

Gráfico 6. Distribución de los subsidios al transporte en colectivo.

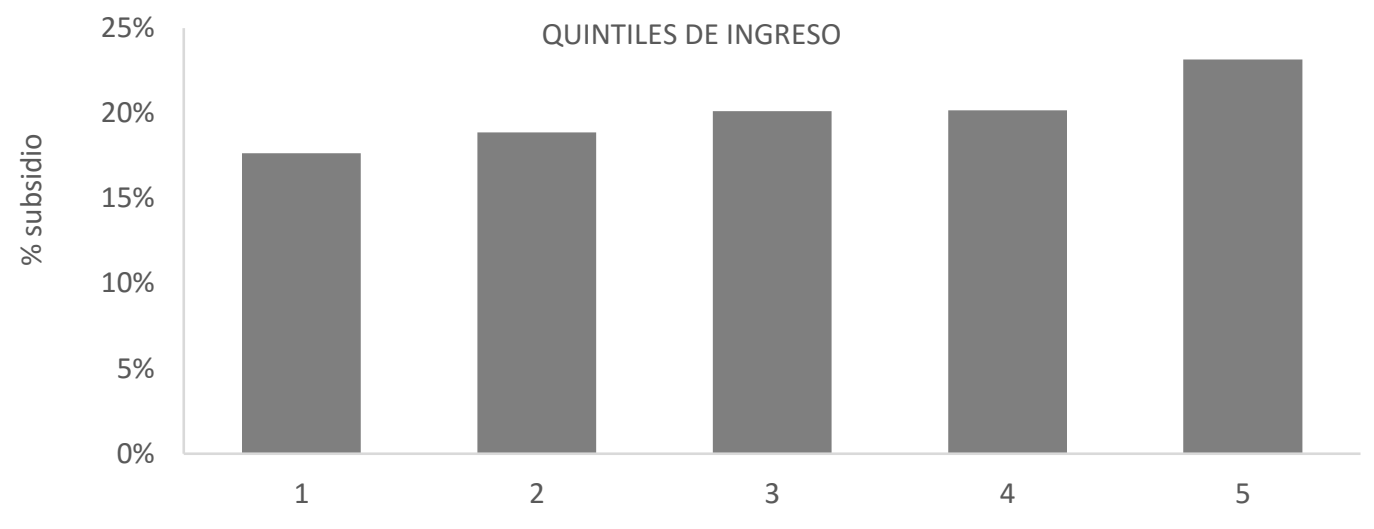

Fuente: elaboración propia.

\footnotetext{
27 Existe otro grupo de beneficiarios de estos subsidios que no se contemplan en este ejercicio dado que la identificación de los mismos resulta imposible dada la información disponible al respecto.

${ }^{28}$ Se considera una tarifa técnica promedio de $\$ 10.28$ por viaje en colectivo y de $\$ 9.23$ por viaje en tren. Fuente: Comisión Nacional de Regulación del Transporte
} 
Gráfico 7. Distribución de los subsidios a al transporte en tren.

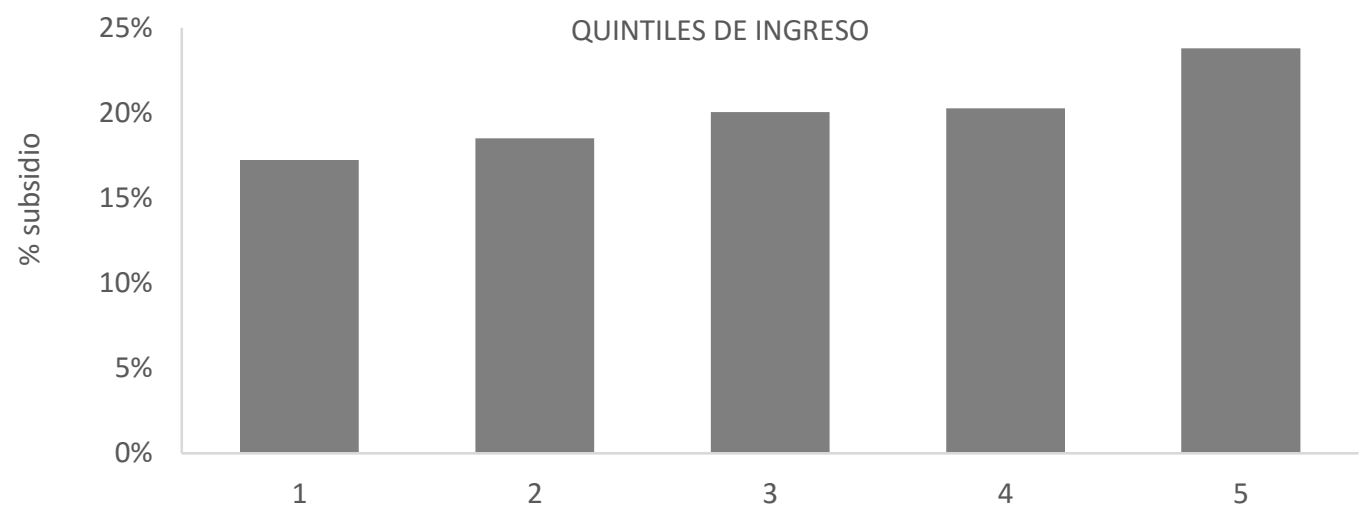

Fuente: elaboración propia.

\section{II.4. Agua y Saneamiento}

\section{II.4.1. Breve descripción del sector}

El consumo de agua se puede caracterizar por dos tipos de regímenes: por un lado, un régimen de consumo medido, cuyo cargo fijo tiende a tener alguna relación con las características de la vivienda, al que posteriormente se le adiciona un costo variable a partir del consumo de metros cúbicos del hogar. Y por otro lado, un régimen que no es medido y se define tomando como referencia el tamaño de la propiedad, en cuanto a la superficie cubierta y del terreno. Además, se utiliza una regla basada en el valor catastral.

Hacia fines del año 2014 se diseña para la Ciudad Autónoma de Buenos Aires y 17 partidos del Gran Buenos Aires (principal zona de influencia de Agua y Saneamientos Argentinos S.A., principal receptora de las transferencias de carácter económico), una tarifa social tendiente a beneficiar a los hogares más vulnerables de dicha región. Este mecanismo se caracteriza por definir el criterio de inclusión al programa a partir del ingreso disponible del hogar, definido éste como la diferencia entre el ingreso total del hogar y el gasto del mismo en salud y vivienda (Cerutti y Quarteroni, 2016).

Siguiendo el criterio del Ente Regulador de Agua y Saneamiento (ERAS), para determinar si el hogar es elegible para ser beneficiario de la tarifa social, se compara su ingreso disponible con un valor de referencia predeterminado: en este estudio, el valor de referencia es de dos jubilaciones mínimas (en caso de que el hogar esté compuesto por una sola persona), extendiéndose en una jubilación mínima adicional por cada habitante extra del hogar ${ }^{29}$.

\footnotetext{
${ }^{29}$ El monto de la jubilación mínima utilizado es de \$2.477, monto de Septiembre 2013 (valor comparable con la encuesta utilizada).
} 
Por otra parte, para definir el descuento pertinente aplicable a cada hogar elegible en el programa de tarifa social, se tiene en cuenta la composición de gasto del mismo, particularmente en servicios optativos (teléfono fijo y celular, internet y televisión por cable). Se estima que un mayor gasto en estos servicios, representa menores necesidades de ayuda económica vinculadas al consumo de servicios públicos. Los descuentos correspondientes para cada nivel de gasto en servicios optativos se describen en la Tabla 2.

Tabla 2. Descuentos para cada nivel de gasto en servicios optativos.

Gasto en servicios optativos Asignación del descuento

\begin{tabular}{|cc|}
\hline$<3 \%$ & $100 \%$ \\
$>3 \% \mathrm{y}<6 \%$ & $60 \%$ \\
$>6 \%$ & $30 \%$ \\
\hline
\end{tabular}

Fuente: Cerutti y Quarteroni (2016) y Ente Regulador del Agua y Saneamiento.

Entonces, de la manera descrita previamente, se obtienen de forma teórica los beneficiarios de la tarifa social y posteriormente se procede a realizar el ejercicio de incidencia detallado a continuación en la sección II.4.2.

\section{II.4.2. Incidencia distributiva}

En este caso, para estimar la incidencia se utiliza la ENGHo para obtener el gasto en el servicio de agua de cada hogar sólo para los usuarios de Capital Federal y Gran Buenos Aires. Se implementa la tarifa social diseñada hacia fines de 2014, y se evalúa la incidencia distributiva presentándose sus resultados en el Gráfico 8. En el caso de los subsidios al agua, se observa que la tarifa social presenta un buen esquema de focalización, alcanzando resultados de incidencia distributivos en favor de los quintiles más vulnerables de la población.

Gráfico 8. Distribución de los subsidios al agua.

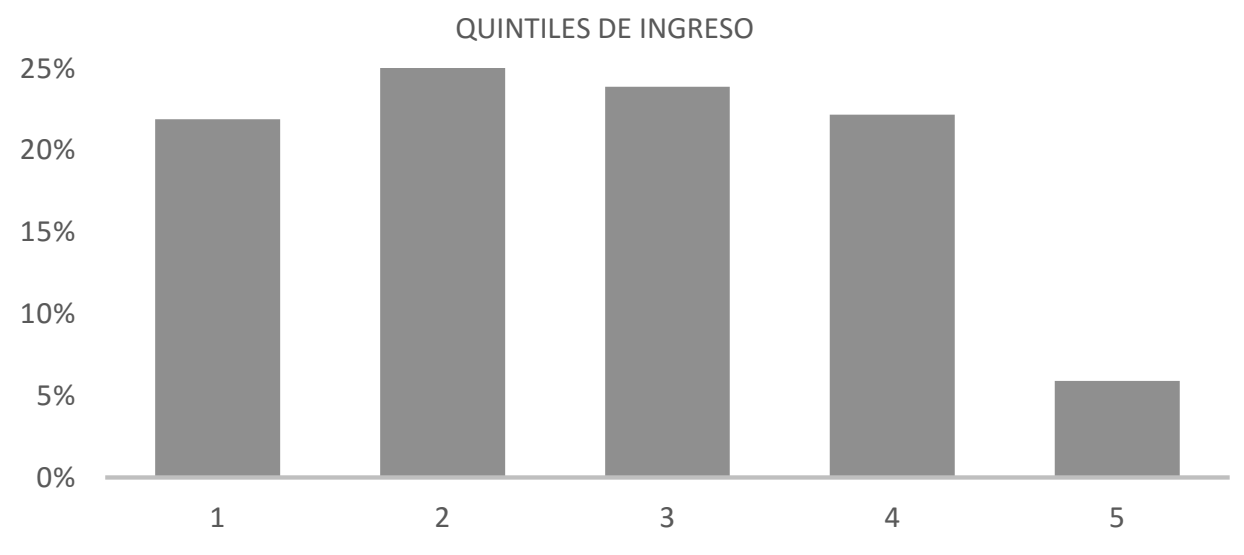

Fuente: elaboración propia. 


\section{II.5. Incidencia conjunta de los servicios públicos}

Una vez realizado el análisis de incidencia distributiva de los subsidios a cada servicio público, se pretende obtener un resultado acerca de cuál es la incidencia de los subsidios a nivel agregado. El Gráfico 9 presenta este ejercicio y se confirma que la política de subsidios llevada a cabo en los últimos años por el Estado argentino benefició mayoritariamente a aquellos hogares con mayores ingresos, poniendo en manifiesto el importante problema de focalización de los subsidios, que motivó el presente estudio.

Gráfico 9. Incidencia distributiva agregada de los subsidios a los servicios públicos.

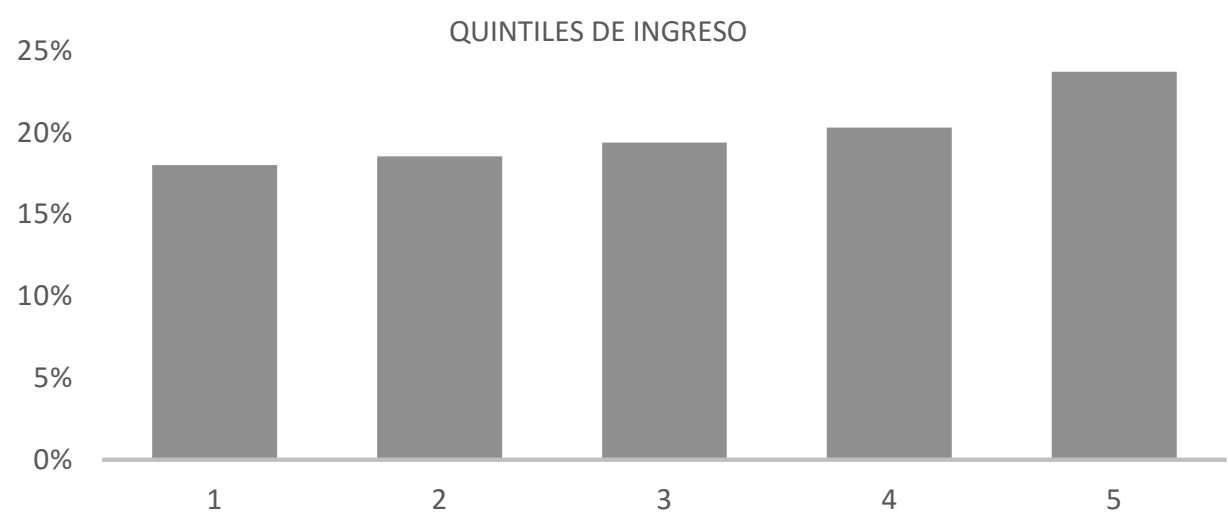

Fuente: elaboración propia.

\section{Escenarios de reforma en pos de una mejora en la focalización de los subsidios.}

A lo largo de la sección anterior se llevó a cabo un análisis del esquema pre reformas (vigente hacia fines del año 2015) de los subsidios a los servicios públicos en Argentina, haciéndose foco en la incidencia distributiva de los mismos. Como se pudo verificar, dichos subsidios presentaron un comportamiento pro-rico casi en su totalidad, poniéndose de manifiesto sus problemas de focalización.

En un intento de mejorar este último aspecto, la presente sección tiene como finalidad ensayar una serie de reformas de los subsidios a los servicios públicos con la intención de alcanzar mejoras en su focalización y consecuente impacto distributivo. Las reformas propuestas tienen la finalidad de sustituir el esquema de subsidios generalizados al consumo de los distintos servicios, por una tarifa social dirigida a grupos específicos. La Tabla 3 presenta un resumen con las reformas a ensayar. 
Tabla 3. Escenarios de reforma propuestos en este trabajo.

\begin{tabular}{|c|c|c|c|}
\hline $\begin{array}{c}\text { Escenario } \\
\mathrm{s}\end{array}$ & Electricidad & Gas de Red & Transporte (Colectivo y Tren) \\
\hline 1 & $\begin{array}{c}\text { Subsidio total para los } \\
\text { primeros } 150 \mathrm{KW} \\
\text { consumidos (mensualmente) } \\
\text { (Esquema de bajo } \\
\text { consumo/Low-User Scheme } \\
\text { no condiciondo). }\end{array}$ & $\begin{array}{c}\text { Subsidio total para los } \\
\text { primeros } 100 \mathrm{~m} 3 \text { consumidos } \\
\text { (mensualmente) (Esquema de } \\
\text { bajo consumo/Low-User } \\
\text { Scheme no condicionado). }\end{array}$ & \multirow{2}{*}{$\begin{array}{l}\text { Tarifa social, asociada a las } \\
\text { condiciones de SUBE (AUH, } \\
\text { Jubilados, Domésticos, } \\
\text { Progresar) + Benef. De planes } \\
\text { sociales+ aumento del } \\
\text { descuento de tarifa } \\
\text { convencional al } 55 \% .\end{array}$} \\
\hline 2 & $\begin{array}{l}\text { Subsidio total para los } \\
\text { primeros } 150 \mathrm{KW} \\
\text { consumidos, sólo para } \\
\text { hogares vulnerables } \\
\text { (mensualmente) (Esquema } \\
\text { de bajo consumo/Low-User } \\
\text { Scheme condiciondo). }\end{array}$ & $\begin{array}{c}\text { Subsidio total para los } \\
\text { primeros } 100 \mathrm{~m} 3 \text { consumidos, } \\
\text { sólo para hogares vulnerables } \\
\text { (mensualmente) (Esquema de } \\
\text { bajo consumo/Low-User } \\
\text { Scheme condicionado). }\end{array}$ & \\
\hline
\end{tabular}

Fuente: Elaboración propia.

\section{III.1. Electricidad: dos reformas propuestas.}

Para el sector eléctrico, se estudian dos posibles escenarios de reforma en pos de la mejora en la focalización ${ }^{30}$. En primer lugar, se define un primer esquema de subsidio pleno a los primeros 150 $\mathrm{KW}$ de consumo mensual residencial para todos los usuarios del servicio (esquema de bajo consumo / Low-User Scheme no condicionado). El Gráfico 10 muestra los resultados de incidencia distributiva de dicho escenario. Estos ponen de manifiesto que eliminando el esquema pre reforma de los subsidios al consumo de energía eléctrica residencial, e implementando un esquema en el cual se subsidien de manera plena los primeros $150 \mathrm{KW}$ de consumo, la focalización de los mismos tiende a mejorar, si bien no se logra un resultado pro-pobre más adecuado para éste tipo de políticas.

\footnotetext{
${ }^{30}$ La cantidad de reformas propuestas no es exhaustiva. Este tipo de ejercicios requiere distintas pruebas para alcanzar el modelo óptimo de focalización.
} 
Gráfico 10. Distribución de los subsidios a la electricidad. Escenario de reforma $\mathbf{N}^{\circ} 1$ : subsidio total para los primeros $150 \mathrm{KW}$ (no condicionado).

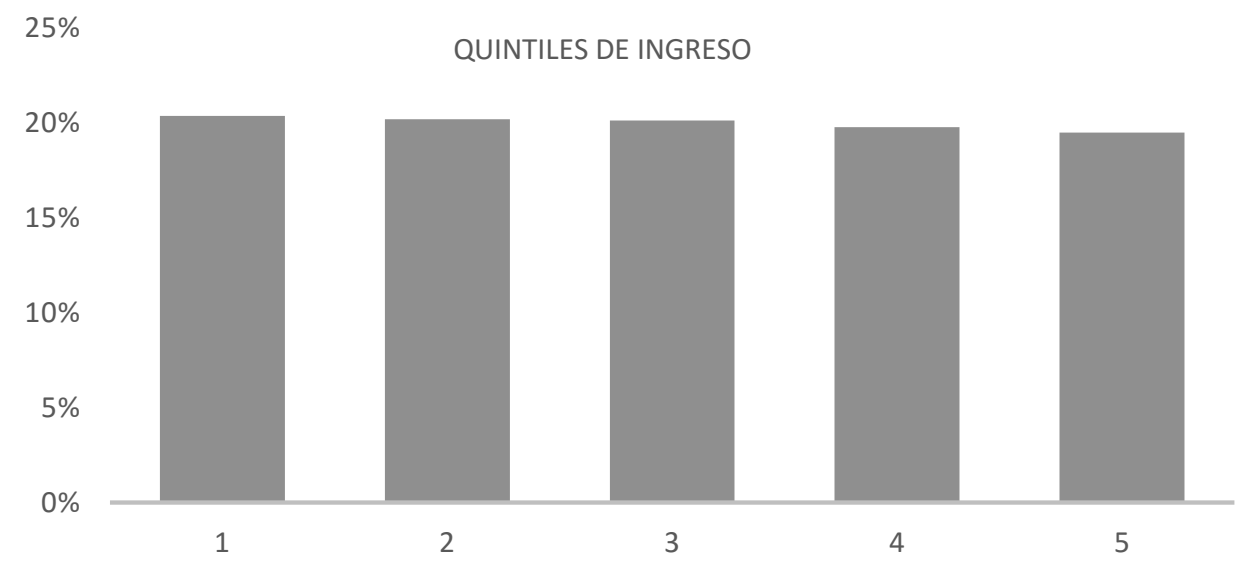

Fuente: elaboración propia.

A partir del resultado del ejercicio precedente, surge la necesidad de mejorar aún más el enfoque de dichos subsidios, por lo cual en segundo lugar se procede a ensayar un esquema de subsidio pleno para los primeros $150 \mathrm{KW}$ de consumo mensual residencial, pero en esta oportunidad focalizado sobre aquellos hogares que se encuentren en condiciones de vulnerabilidad, entendido esto último como aquellos receptores de los programas “Asignación Universal por Hijo", "Progresar" y "Programa Hogar" (Esquema de bajo consumo/Low-User Scheme condicionado). En el Gráfico 11 se pueden ver los resultados de incidencia distributiva del nuevo escenario.

Gráfico 11. Distribución de los subsidios a la electricidad. Escenario de reforma $\mathbf{N}^{\circ} 2$ : subsidio total para los primeros $150 \mathrm{KW}$, sólo para hogares vulnerables (condicionado).

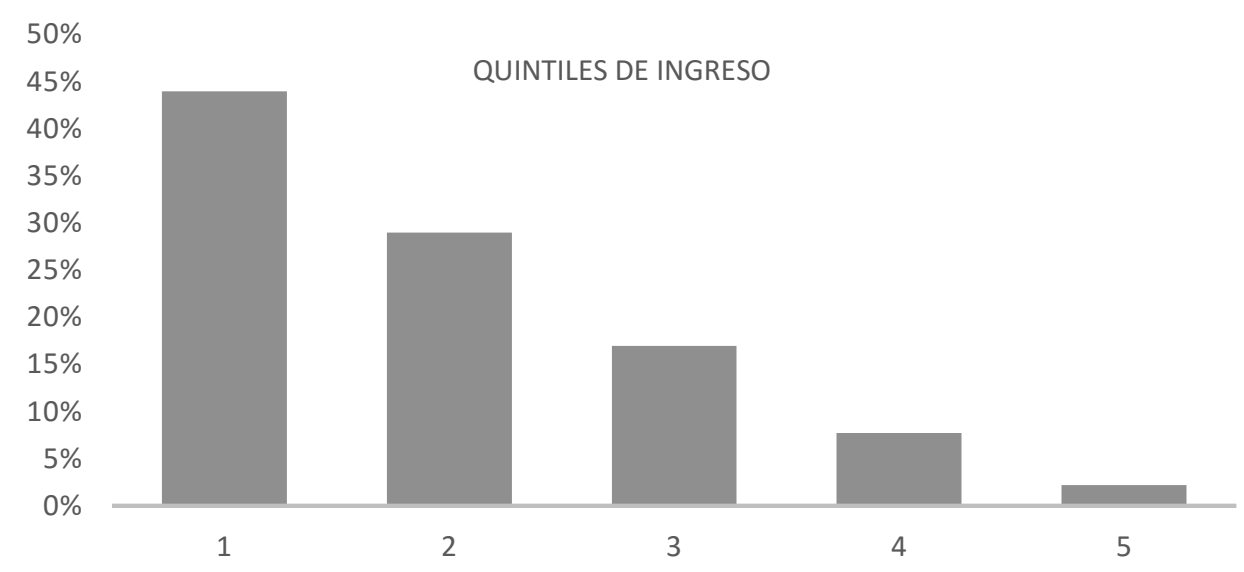

Fuente: elaboración propia.

El ejercicio anterior muestra que la focalización de los subsidios a la electricidad puede ser mejorada si se identifica, siguiendo algún criterio específico, aquellos hogares vulnerables que se encuentran 
en los primeros quintiles de la distribución del ingreso. Con esta propuesta de reforma (Esquema de bajo consumo/Low-User Scheme condicionado), se reduce considerablemente el error de inclusión y exclusión, alcanzando de manera más efectiva a aquellos hogares que realmente se ven imposibilitados de afrontar tarifas más altas. A continuación, en el Gráfico 12 se observa la cobertura de la reforma llevada a cabo, por quintil de ingreso.

Gráfico 12. Cobertura del escenario de reforma $\mathbf{N}^{\circ}$ 2: subsidio total para los primeros $150 \mathrm{KW}$, sólo para hogares vulnerables (condicionado).

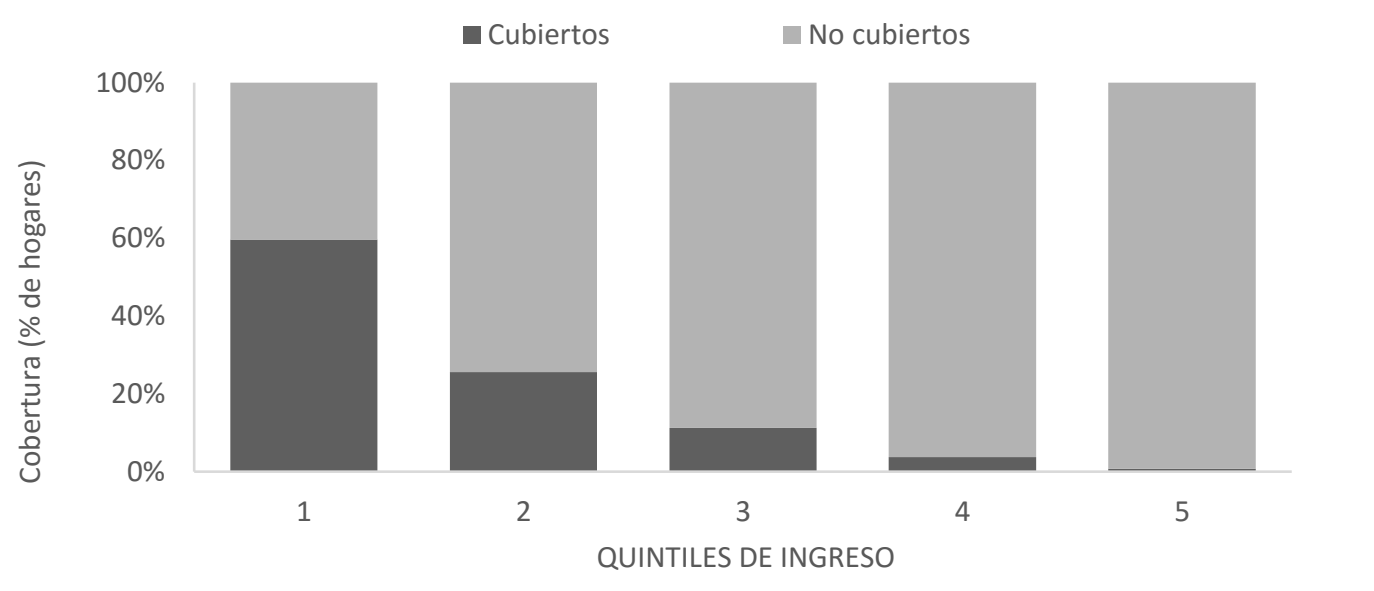

Fuente: elaboración propia.

La reforma precedente, resulta pro-pobre y logra alcanzar en un porcentaje mayor a hogares en condiciones de vulnerabilidad. Esta propuesta se trata de una sugerencia que muestra un resultado en línea con el objetivo final de este tipo de políticas.

A modo de conclusión para el análisis de reformas de los subsidios al consumo de electricidad residencial, se presenta en el Gráfico 13 un análisis comparado entre el status quo y los dos escenarios de reforma ya propuestos. En el mismo, se observa la ventaja que presenta el escenario 2 (Esquema de bajo consumo/Low-User Scheme condicionado) en cuanto a su mejora en la focalización, alcanzándose un esquema de subsidios pro-pobre. Este resultado, además, se encuentra en línea con el ranking de resultados de Marchionni et al. (2008) en donde se verifica la superioridad del Esquema de bajo consumo/Low-User Scheme (LUS) condicionado respecto a un esquema LUS no condicionado. 
Gráfico 13. Incidencia: status quo y escenarios de reforma (comparación), sector eléctrico residencial.

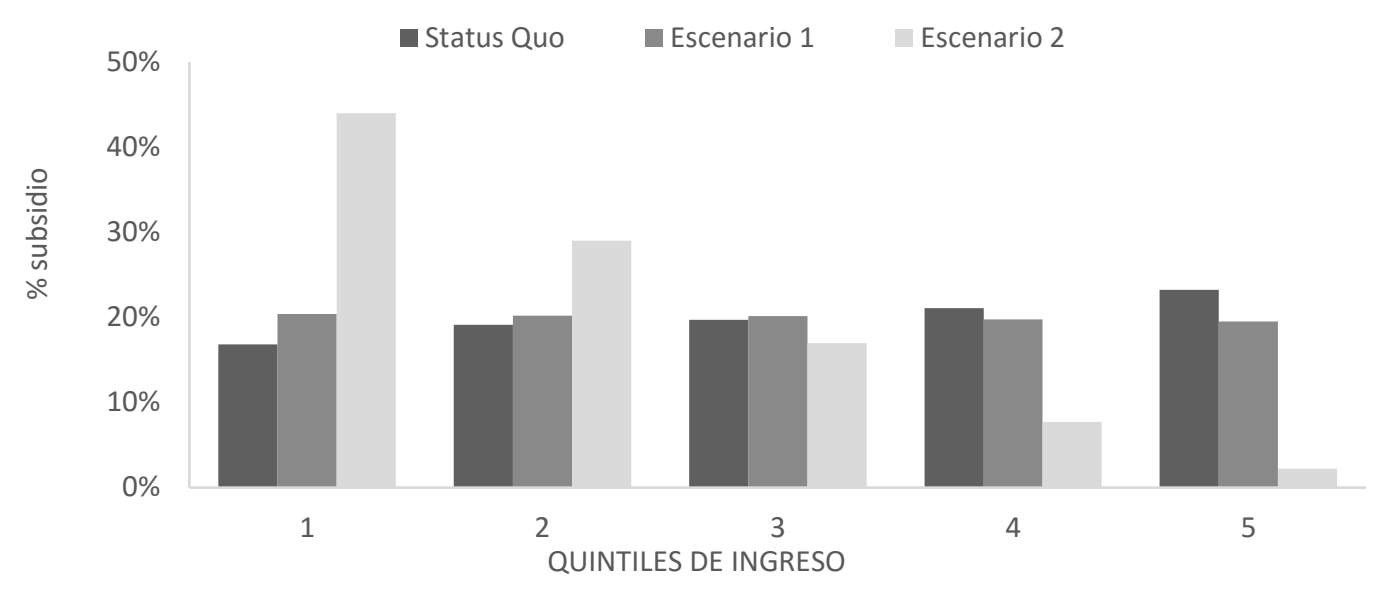

Fuente: elaboración propia. Escenario 1: Esquema de bajo consumo no condicionado. Escenario 2: Esquema de bajo consumo condicionado.

\section{III.2. Gas de red: dos reformas propuestas.}

Para el caso del gas de red, también se ensayan dos posibles reformas con la intención de alcanzar una mejora en la focalización. En primer lugar, se evalúa un primer escenario el cual consta de otorgar un subsidio pleno a toda la población, sobre los primeros $100 \mathrm{M} 3$ de consumo residencial mensuales (Esquema de bajo consumo/Low-User Scheme no condicionado). El Gráfico 14 muestra el ejercicio de incidencia distributiva del mencionado escenario. Se puede observar que la reforma planteada en este caso no estaría mejorando sustancialmente la focalización del subsidio residencial al gas de red.

Gráfico 14. Distribución de los subsidios al gas de red. Escenario de reforma $\mathrm{N}^{\circ}$ 1: subsidio total para los primeros $100 \mathrm{M} 3$ de consumo (no condicionado).

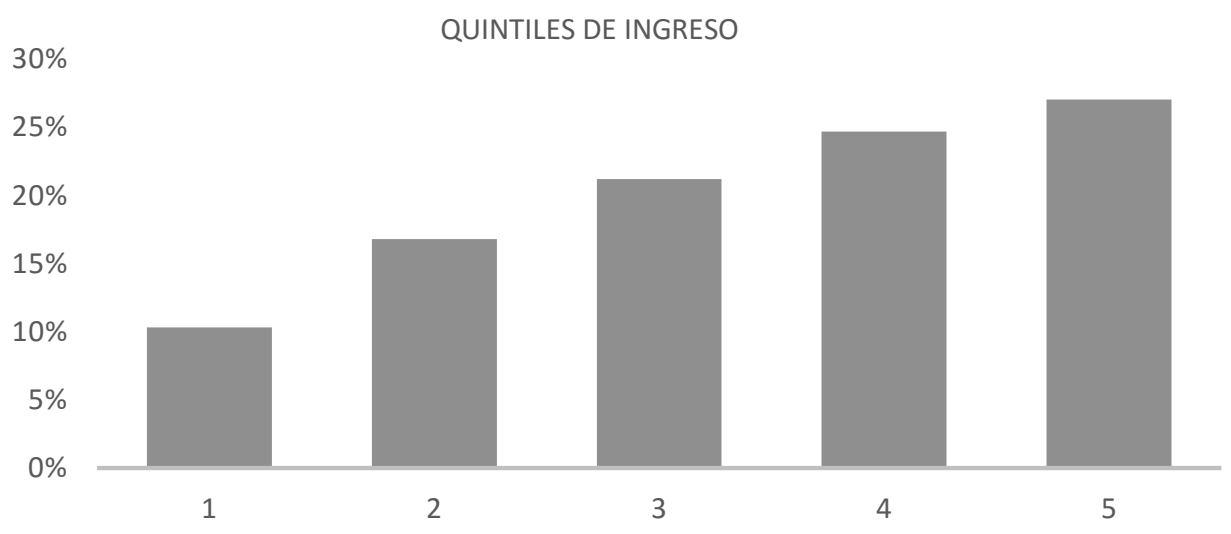

Fuente: elaboración propia. 
Es por lo anterior que surge la necesidad de realizar un análisis más detallado a la hora de identificar a la población objetivo, potencial receptora del beneficio. En línea con esto, se ensaya el segundo escenario, el cual consiste en otorgar un subsidio pleno para los primeros $100 \mathrm{M} 3$ de consumo mensual residencial, pero en esta oportunidad focalizado sobre aquellos hogares que se encuentren en condiciones de vulnerabilidad, entendido esto último como aquellos receptores de los programas "Asignación Universal por Hijo" y "Progresar" 31 (Esquema de bajo consumo/Low-User Scheme condicionado). El estudio de incidencia distributiva se muestra en el Gráfico 15. Se observa que al mejorar la focalización de la política de subsidios al gas de red, los resultados se tornan favorables en el sentido de una mejora en su impacto distributivo. Los primeros quintiles de la población, aquellos hogares más vulnerables, reciben las mayores transferencias destacando el carácter propobre de este escenario de reforma. Este resultado coincide con aquel encontrado por Navajas (2007), quien evalúa el poder distributivo de un Esquema de bajo consumo/Low-User Scheme no condicionado en el caso de gas natural y confirma que este tipo de esquemas poseen un bajo poder distributivo respecto a un Esquema de bajo consumo/Low-User Scheme condicionado.

Gráfico 15. Distribución de los subsidios al gas de red. Escenario de reforma $\mathrm{N}^{\circ}$ 2: subsidio total para los primeros 100 M3 de consumo, sólo para hogares vulnerables (condicionado).

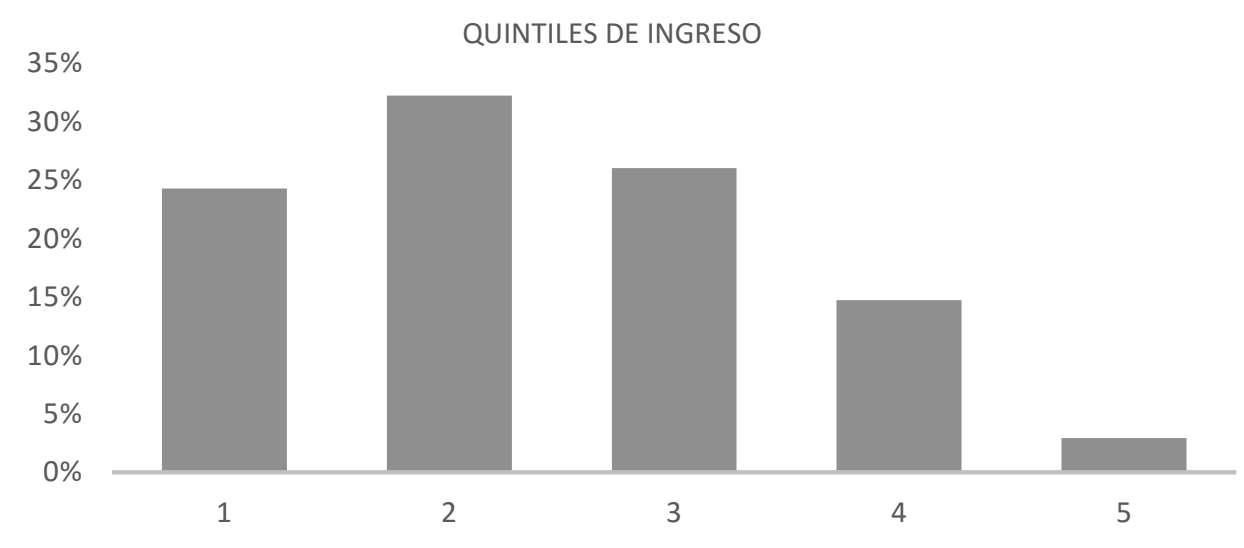

Fuente: elaboración propia.

Luego de evaluar el impacto distributivo de las dos alternativas de reforma, se realiza un análisis conjunto en donde se observa el statu quo y se lo compara con los nuevos esquemas. Una vez más se verifica que, mejorando el criterio de focalización de la política de subsidios, se logran mejores resultados distributivos. Los resultados se muestran en el Gráfico 16.

\footnotetext{
${ }^{31}$ En este caso, no se incluye el hecho de que los hogares formen parte del "Programa Hogar" como en Electricidad, debido a que es condición para formar parte del mismo el no estar conectado al servicio de gas de red.
} 
Gráfico 16. Incidencia: status quo y escenarios de reforma, gas de red residencial.

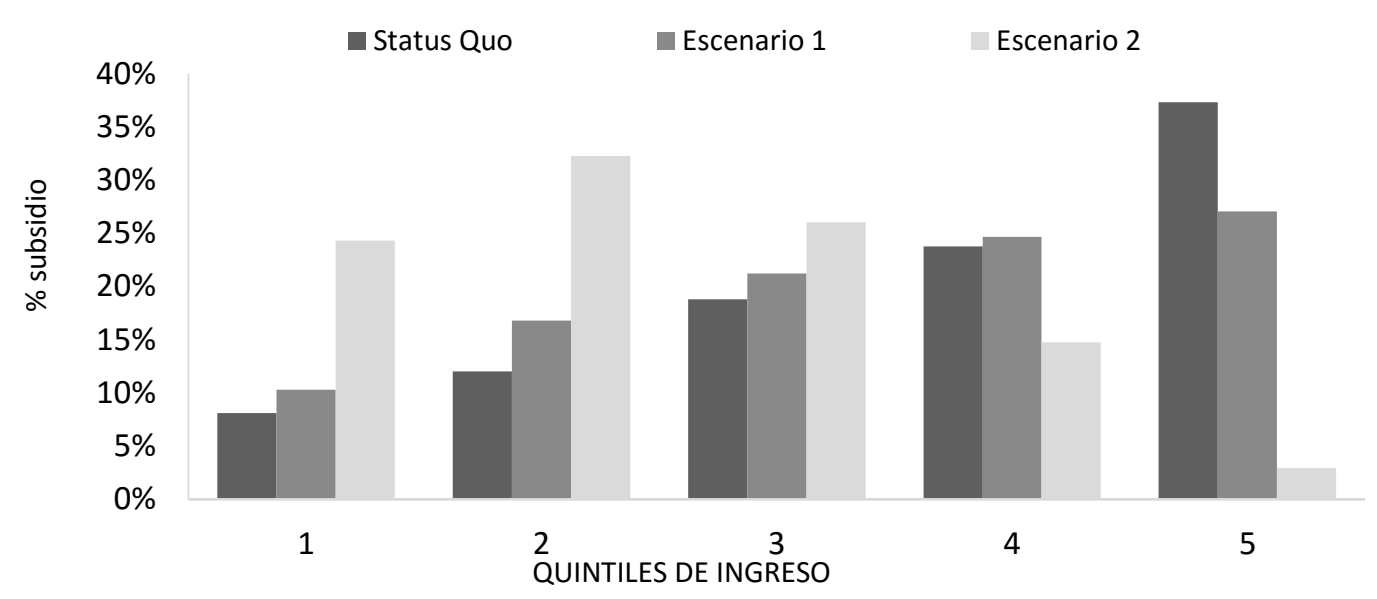

Fuente: elaboración propia. Escenario 1: esquema de bajo consumo no condicionado. Escenario 2: esquema de bajo consumo condicionado.

\section{III.3. Transporte}

El cambio tarifario vigente desde el 8 de abril de 2016 se caracteriza como su precedente, por subsidios generalizados con acento en grupos específicos. La modificación tarifaria tiene como correlato nuevas asignaciones de subsidios entre los usuarios del servicio. El nuevo cuadro tarifario incluye aumentos en la tarifa convencional y en la tarifa social, y mantenimiento de la tarifa estudiantil. Para el caso de la tarifa social, a los nuevos valores tarifarios, se amplió el descuento sobre la tarifa convencional del $40 \%$ al $55 \%^{32}$.

Los Gráficos 17 y 18 exponen la incidencia distributiva de este nuevo escenario para el transporte en colectivo y tren, y su comparación con la incidencia del status quo. Los cambios implementados a partir del año 2016 en cuanto a la configuración de subsidios al transporte, no genera modificaciones relevantes desde el punto de vista distributivo, tanto para colectivo como para tren.

32 Las nuevas tarifas técnicas son $\$ 13.36$ promedio por viaje en colectivo y $\$ 12$ promedio por viaje en tren. Fuente: Comisión Nacional de Regulación del Transporte. 
Gráfico 17. Incidencia: status quo y escenarios de reforma, transporte de colectivo.

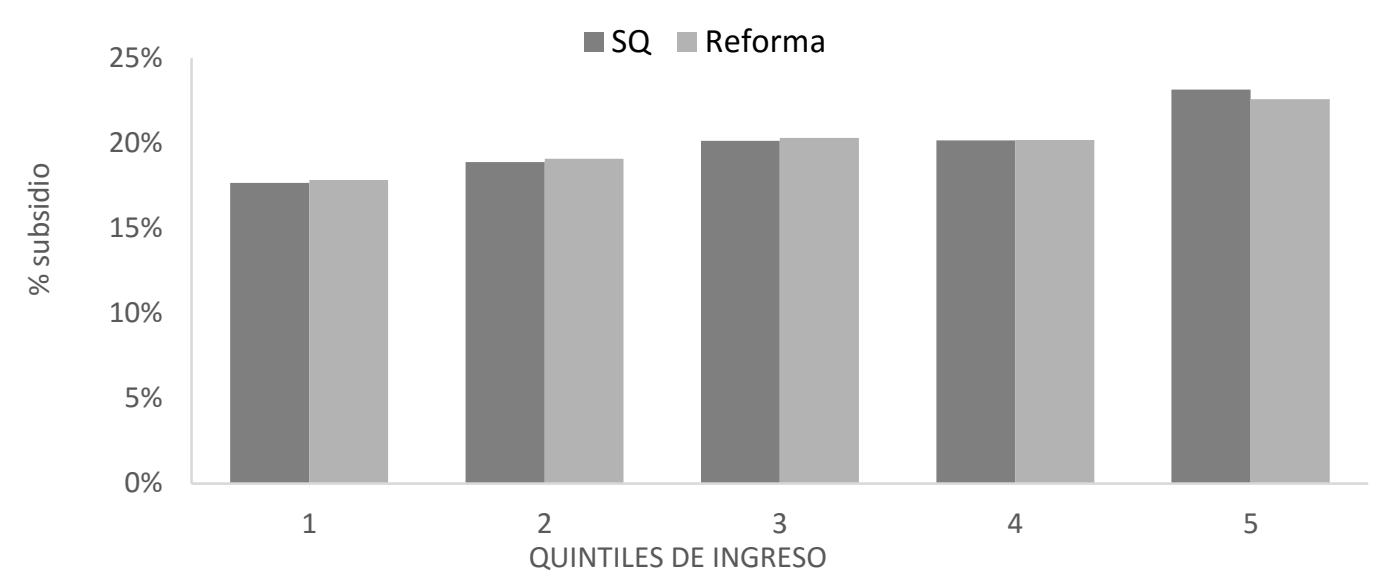

Fuente: elaboración propia.

Gráfico 18.

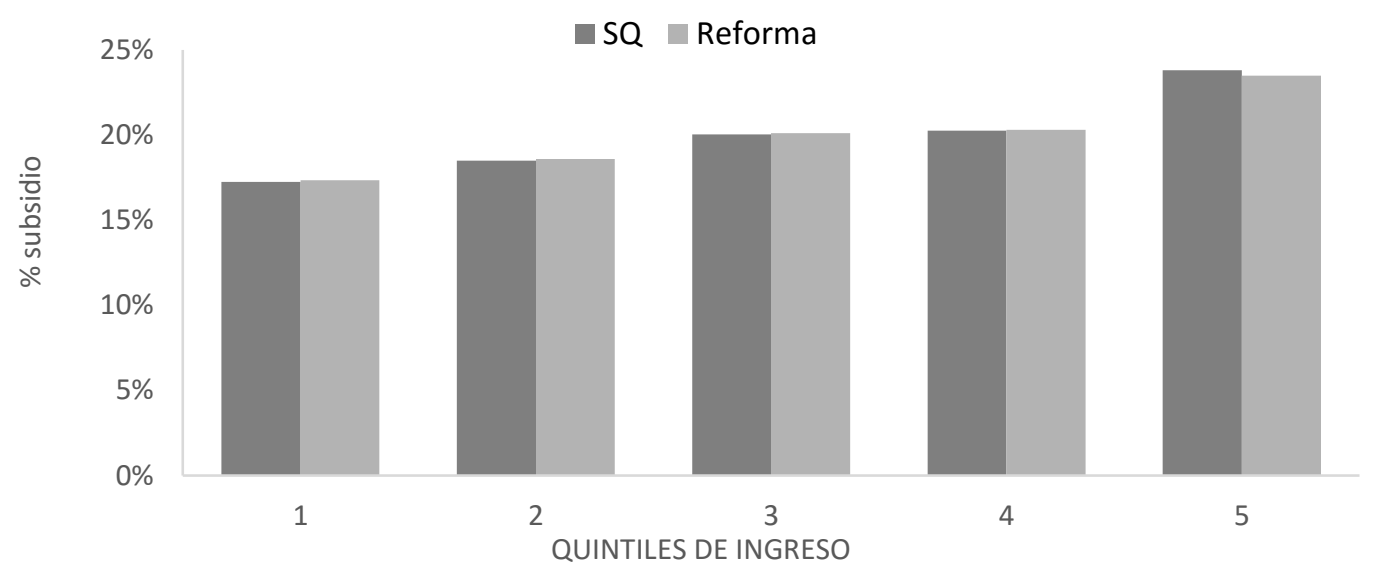

Fuente: elaboración propia.

Una de las principales razones por la cual se deduce este resultado de incidencia distributiva es que se incluye al grupo de jubilados como beneficiarios de la tarifa social. Este grupo de individuos se caracteriza por presentar una distribución del ingreso que se concentra en los quintiles más altos de la población. El Gráfico 19 muestra esta situación.

El ejercicio llevado a cabo revela, una vez más, que aún existe espacio considerable de mejora en el diseño de la política de subsidios, inclusive en el sector de transporte público terrestre. 
Gráfico 19. Distribución del subsidio: jubilados. Status quo y reforma.

Jubilados (Colectivo)

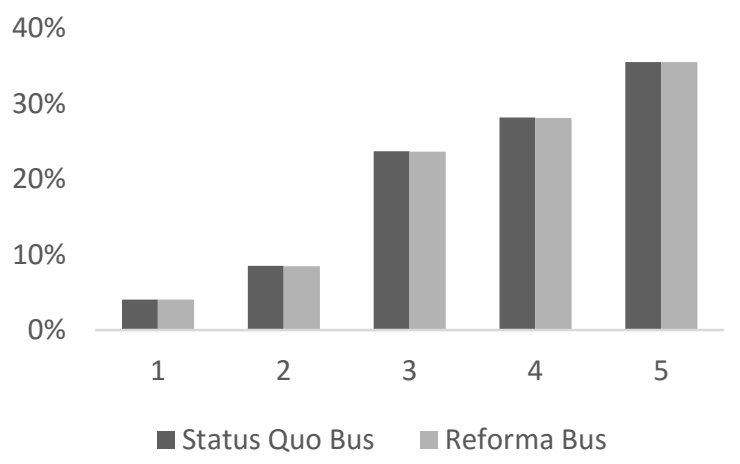

Jubilados (Tren)

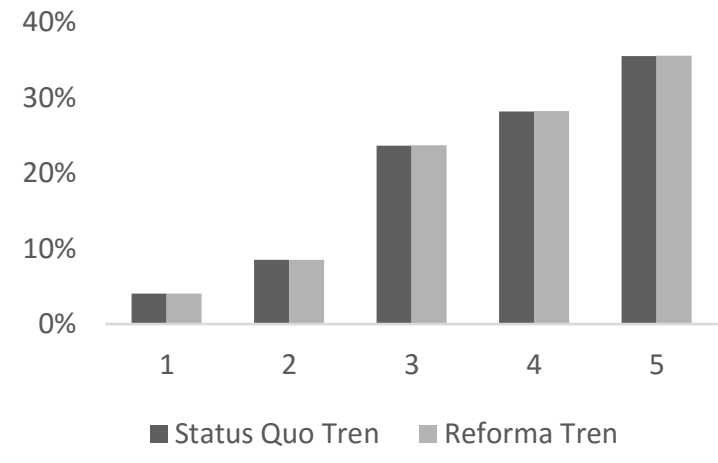

Fuente: elaboración propia.

\section{III.4. Incidencia conjunta de los escenarios de reforma a los servicios públicos.}

A continuación se procede a ensayar el mismo ejercicio que en la sección II.5., considerando el total de las reformas ensayadas. El Gráfico 20 muestra los resultados de incidencia distributiva de los subsidios a los servicios públicos de manera agregada.

Como se puede observar, a partir de las reformas propuestas, se puede alcanzar una mejora sustancial en la focalización de la política de subsidios a los servicios públicos. A pesar de ello, el desafío es importante y es necesario continuar indagando acerca de las posibles alternativas de diseño de política que permitan alcanzar aún mejores resultados distributivos en este aspecto.

Gráfico 20. Incidencia distributiva agregada de los escenarios de reforma a los servicios públicos ${ }^{33}$

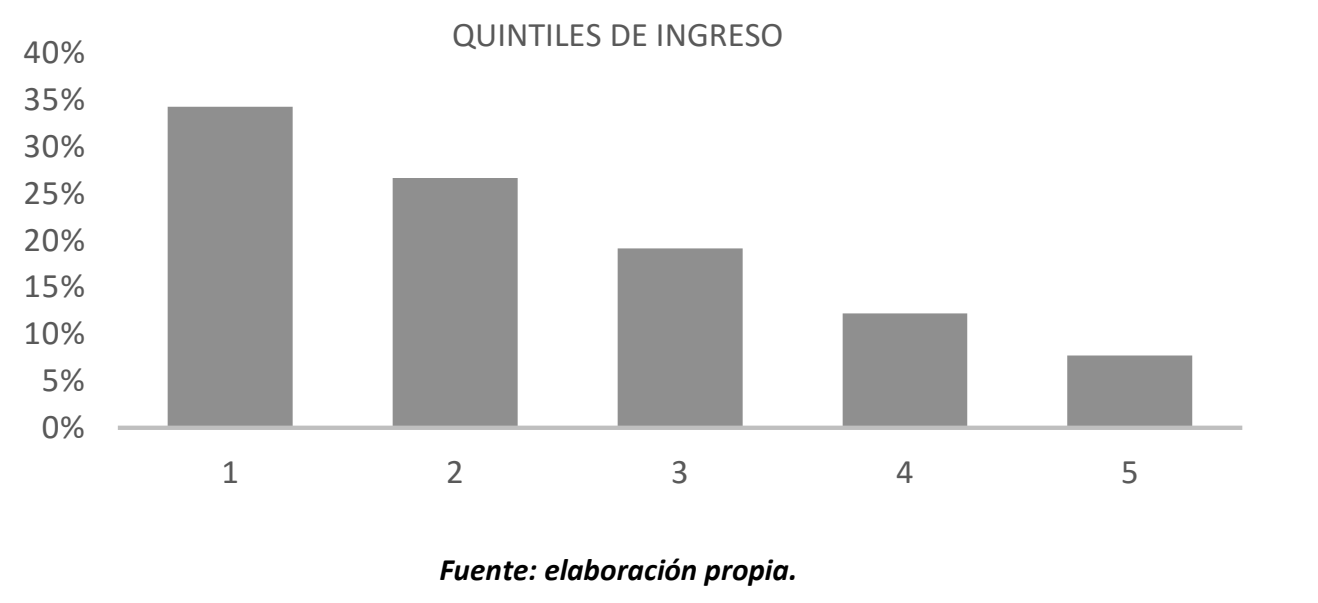

\footnotetext{
${ }^{33}$ Se utilizan el escenario 2 (Esquema de bajo consumo/Low-User Scheme condicionado) para Electricidad y Gas de Red, status quo para el servicio de Agua y el único escenario ensayado para Transporte.
} 


\section{Conclusiones}

Desde el año 2006, Argentina llevó adelante una importante política de subsidios a los servicios públicos que significó erogaciones que llegaron a alcanzar hasta cinco puntos de su Producto Bruto Interno. Es a partir de esto que surge la necesidad de llevar adelante el presente ejercicio, con la finalidad de evaluar el efecto de ésta política pública y su impacto desde un punto de vista distributivo.

Analizando los subsidios al sector energético, de transporte terrestre y agua, se llega a la conclusión de que los mismos presentaban en 2015 (pre-reformas) un efecto pro-rico en la mayoría de sus configuraciones. Posteriormente, en un intento de mejorar la focalización de los mismos, se ensayan ejercicios de reforma que pretenden subsanar este inconveniente.

Se propone así un cambio en los esquemas de subsidios, en algunos casos replicando aquellas medidas tomadas por el gobierno nacional a partir del año 2016, y en otros ensayando algunas reformas similares a las que se adoptaron en otros países del mundo. Específicamente, se implementan esquemas de bajo consumo condicionados y no condicionados (Low-User Schemes) y se evalúa su impacto distributivo.

Lo que se obtiene luego de las reformas y a partir de la utilización de los esquemas de bajo consumo condicionados, es una mejora en la focalización de la mayoría de los subsidios a los servicios públicos.

El presente trabajo pretende ser un avance en la literatura sobre estos tópicos, en tanto utiliza los cambios institucionales ocurridos en la Argentina en los últimos meses, permitiendo focalizar condicionadamente a programas que antes no se encontraban del todo desarrollados o generalizados, y utiliza los datos más recientes sectoriales y de la ENGHo, que brindan además la posibilidad de extender el análisis a todo el país. Una posible extensión del presente trabajo podría surgir a partir de evaluar si las reformas han sido bien diseñadas y si las mismas pueden ser superadas por otros esquemas ${ }^{34}$.

Se concluye, que para alcanzar una mejora en la focalización de este tipo de políticas públicas, es críticamente importante utilizar los criterios apropiados o proxis necesarias para llegar a los grupos más vulnerables, y considerar los desafíos que acarrea su implementación.

\footnotetext{
${ }^{34}$ La implementación de esquemas de suma fija que no involucren esquemas de bajo consumo a precio cero podría ser una alternativa a evaluar.
} 


\section{Referencias bibliográficas}

Ángel-Urdinola, D. \& Wodon, Q., (2005). “Do Utility Subsidies Reach the Poor? Framework and Evidence for Cape Verde", Washington DC: Banco Mundial.

Barafini, M. y Castro, L. (2015). “Buscando la diagonal. Cómo reducir los subsidios protegiendo a los sectores vulnerables". CIPPEC.

Campoy, D. (2015). "Análisis distributivo del subsidio al consumo eléctrico residencial. Caso Argentino". Trabajo de Tesis de Maestría en Economía.

Cerutti, S. y Quarteroni, M. (2016). "Subsidios al agua en Argentina: esquemas alternativos y su incidencia". Maestría en Economía, Facultad de Ciencias Económicas de la Universidad Nacional de La Plata.

Coady, D., Grosh, M. \& Hoddinott, J., (2003). "Targeting of Transfers in Developing Countries: Review of Lessons and Experience", Washington DC: Banco Mundial.

Cont, W. (2008). "La tarifa social en electricidad en las provincias argentinas", Capítulo 4 en Navajas (editor) (2008).

Cont, W., Hancevic, P., Navajas, F. (2008). "Infraestructura y aspectos distributivos en la tarificación de los servicios públicos: ámbito y posibilidades de la tarifa social en la Argentina". Documento de Trabajo 2008/3. CAF.

Flood, C., Harriague, M., Gasparini, L., y Vélez B. (1994)." El gasto público social y su impacto redistributivo". Secretaría de Programación Económica. Ministerio de Economía.

Gasparini, L., Cicowiez, M. y Sosa Escudero, W. (2012). "Pobreza y desigualdad en América Latina”. 1a ed. - Buenos Aires: Temas Grupo Editorial, 2012.

Gasparini, L., y Porto, A. (1995). “Medidas de equidad y política fiscal: Teoría y una Aplicación”. En A. Porto (Ed.), Finanzas Públicas y Economía Espacial (pp. 137-159). Argentina: UNLP.

Hancevic P. y F. Navajas (2008), “Adaptación tarifaria y tarifa social: simulaciones para el gas natural y la electricidad en el AMBA", Capítulo 3 en Navajas (editor) (2008).

Hancevic, P., Cont, W. y Navajas, F. (2016), "Energy populism and household welfare", Energy Economics, vol. 56, pp. 464-74, May.

Lombardi, M., Mongan, J., Puig, J. y Salim, L. (2014). “Una aproximación a la focalización de los subsidios a los servicios públicos en Argentina". Documento de Trabajo DPEPE N 09/2014. Ministerio de Economía de la Provincia de Buenos Aires.

Marchionni, M. et al. (2008). "Efectos Distributivos de Esquemas Alternativos de Tarifas Sociales: Una exploración Cuantitativa". CEDLAS, Documento de trabajo nro. 68. 
Marchionni, M. et al. (2008). "La incidencia distributiva del acceso, gasto y consumo de los servicios públicos". CEDLAS, Documento de Trabajo nro. 67.

Navajas, F. (2007). “Engel Curves, Household Characteristics and Low-User Tariff Schemes in Natural Gas". FIEL.

Navajas, F. (2015). "Subsidios a la energía, devaluación y precios". Documento de trabajo nro 122. FIEL.

Navajas, F. (ed.) (2008). "La Tarifa Social en los Sectores de Infraestructura en la Argentina". Buenos Aires: Editorial TESIS para FIEL.

Puig, J. y Salinardi, L. (2015). “Argentina y los subsidios a los servicios públicos: un estudio de incidencia distributiva". CEDLAS, Documento de Trabajo nro. 183. 


\section{ANEXO}

\section{La Encuesta Nacional de Gastos de los Hogares (ENGHo)}

La Encuesta Nacional de Gastos de los Hogares 2012/13, la cual fue realizada por el Instituto Nacional de Estadística y Censos (INDEC) de la Argentina y su antecedente inmediato es la realizada en los años 2004 y 2005, se realizó en todo el país entre el 16 de marzo de 2012 y el 19 de marzo de 2013, a través de una muestra probabilística, polietápica y estratificada extraída de la Muestra Maestra Urbana de Viviendas de la República Argentina. De esta muestra maestra, construida a partir del Censo Nacional de Población, Hogares y Viviendas 2010, fueron seleccionadas alrededor de 37.000 viviendas.

El operativo de relevamiento cuenta con una ventana de observación única y completa de 52 semanas consecutivas, constituyendo 12 meses seguidos de relevamiento en campo. El objetivo principal es recabar información acerca de los gastos de los hogares residentes en localidades de 5 mil y más habitantes.

El gasto de consumo de los hogares se distribuye entre diferentes bienes y servicios agrupados según el tipo de necesidades que satisfacen. Además, la Encuesta obtiene datos acerca de gastos no imputables al consumo (es decir, que no satisfacen ninguna necesidad inmediata ni generan una contraprestación para el hogar) y otros de gastos.

La Encuesta permite caracterizar las condiciones de vida de los hogares, fundamentalmente en términos de su acceso a los bienes y servicios. Proporciona, además, información para el cálculo de las ponderaciones del Índice de Precios al Consumidor Nacional urbano (IPCNu) y para las estimaciones de las Cuentas Nacionales, así como para el diseño de políticas públicas.

Las unidades de observación de la encuesta son los hogares particulares residentes en viviendas particulares ubicadas en localidades de cinco mil y más habitantes del país. Se considera hogar particular a aquel constituido por toda persona o grupo de personas, parientes o no, que conviven en una misma vivienda bajo un régimen de tipo familiar y consumen alimentos con cargo al mismo presupuesto. Por otro lado, se considera miembros del hogar a las personas que habitan en una misma vivienda bajo un régimen de tipo familiar, comparten sus gastos de alimentación y habitan la vivienda desde hace 6 o más meses o, si viven en ella hace menos de 6 meses, han fijado o piensan fijar allí su residencia.

Las principales variables de estudio de la encuesta son el gasto y el ingreso de los hogares. Con el fin de definir y analizar diferentes dominios y caracterizar a los hogares que los componen, se releva también información sobre variables demográficas, ocupacionales y educacionales de sus miembros, así como sobre las características de la vivienda, transferencias en especie recibidas y equipamiento del hogar. 
Tabla A1. Transferencias Corrientes a los servicios públicos.

\begin{tabular}{|c|r|r|r|r|r|}
\hline $\begin{array}{c}\text { Subsidios Económicos, } \\
\text { en millones de pesos }\end{array}$ & $\mathbf{2 0 1 1}$ & $\mathbf{2 0 1 2}$ & $\mathbf{2 0 1 3}$ & $\mathbf{2 0 1 4}$ & $\mathbf{2 0 1 5}$ \\
\hline CAMMESA & 23.698 & 24.554 & 33.897 & 71.333 & 89.793 \\
\hline ENARSA & 10.506 & 19.209 & 31.187 & 40.470 & 27.145 \\
\hline Programa Hogar & $\mathrm{n} / \mathrm{d}$ & $\mathrm{n} / \mathrm{d}$ & $\mathrm{n} / \mathrm{d}$ & 11.299 & 11.893 \\
\hline Transporte Automotor & 10.523 & 13.867 & 17.364 & 24.914 & 29.366 \\
\hline Transporte Ferroviario & 6.836 & 13.041 & 11.248 & 12.385 & 16.614 \\
\hline Agua & 3.995 & 5.374 & 7.166 & 2.917 & 3.000 \\
\hline
\end{tabular}

Fuente: elaboración propia en base a datos de ASAP

\section{CUADRO A1: Cuadros Tarifarios}

Mapa de cuadros tarifarios:

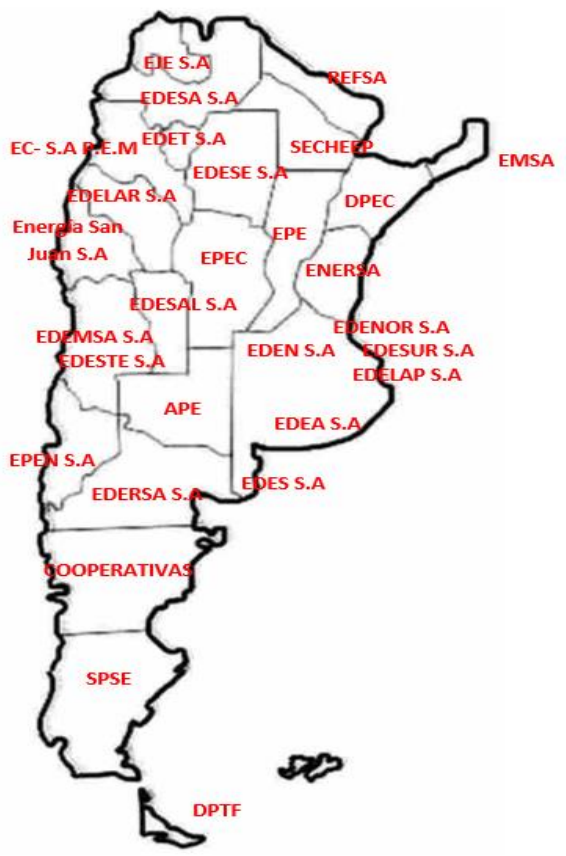

Para cada región, se utiliza un cuadro tarifario representativo debido a que los montos tarifarios no varían considerablemente entre provincias limítrofes. Se utilizarán los cuadros de AMBA, NEA, Pampeana, Cuyo, Patagonia y NOA. 


\section{CUADRO A2: Estimación del consumo físico a partir de la ENGHO}

El gasto observado en la encuesta es el monto total facturado en cada bimestre, que incluye los impuestos correspondientes al área geográfica a la que pertenece el hogar. Es decir, el monto observado en la encuesta es $T_{F}=(1+t) T$, donde $t$ representa la suma de impuestos y tasas correspondientes a la zona de residencia del hogar y $T$ el monto facturado antes de impuestos. Para recuperar el consumo físico se procede, en una primera etapa, a recuperar la factura neta de impuestos descontando las tasas correspondientes a la región de residencia del hogar. La fórmula aplicada para la deducción impositiva es la siguiente:

$$
T^{h}=\frac{T_{F}^{h}}{1+t} \quad h=1, \ldots, H
$$

Donde $t$ es la suma de impuestos y tasas correspondientes a la jurisdicción en la cual reside el hogar $h$. La segunda etapa implica obtener el consumo físico a partir de la factura neta de impuestos. Las fórmulas difieren por servicio.

Teniendo lo anterior en cuenta, primero se estiman los consumos físicos (en $\mathrm{kW}$ ) restando a la factura neta de impuestos el costo fijo y dividiendo este resultado por el costo variable. Esto se realiza para cada tarifa en dos tramos R1 y R2 ${ }^{1}$, obteniéndose dos valores de consumo kWh1 y $\mathrm{kWh} 2$, respectivamente.

Luego se comparan los consumos obtenidos contra un umbral específico ${ }^{1}$ que varía por región y por bimestre, para determinar cuál es la estimación más verosímil siguiendo el siguiente criterio:

$$
k W h=\left\{\begin{array}{c}
\text { si } k W h_{2} \geq X \\
k W h_{2} \\
k W h_{1} \quad \text { si } k W h_{2}<X y k W h_{1} \leq X \\
\text { no se considera el hogar, si } k W h_{2}<X y k W h_{1}>X
\end{array}\right.
$$

\section{CUADRO A3: Configuración de la tarifa de usuarios residenciales}

En general, la tarifa que paga un usuario residencial está compuesta por un mix cargo fijo - cargo variable para remunerar el commodity (energía eléctrica), la capacidad de generación, el transporte y la distribución del servicio. El cargo fijo de la tarifa remunera, normalmente, la capacidad de generación (potencia) y los cargos fijos de distribución. El cargo variable remunera el commodity y los costos variables de distribución. El gasto final incluye impuestos nacionales, provinciales y municipales. En la Argentina existe una gran variedad de esquemas tarifarios producto de la configuración federal de la regulación. Mientras que en las áreas atendidas por las empresas Edenor, Edesur y Edelap la regulación es nacional, a través del Ente Nacional Regulador de la Electricidad (ENRE), en el resto del país la regulación está bajo la órbita de los respectivos entes provinciales reguladores de la electricidad (EPREs). 


\section{CUADRO A4: ¿De dónde se obtiene cada dato?}

A continuación se observa la configuración de los distintos actores del sector eléctrico:

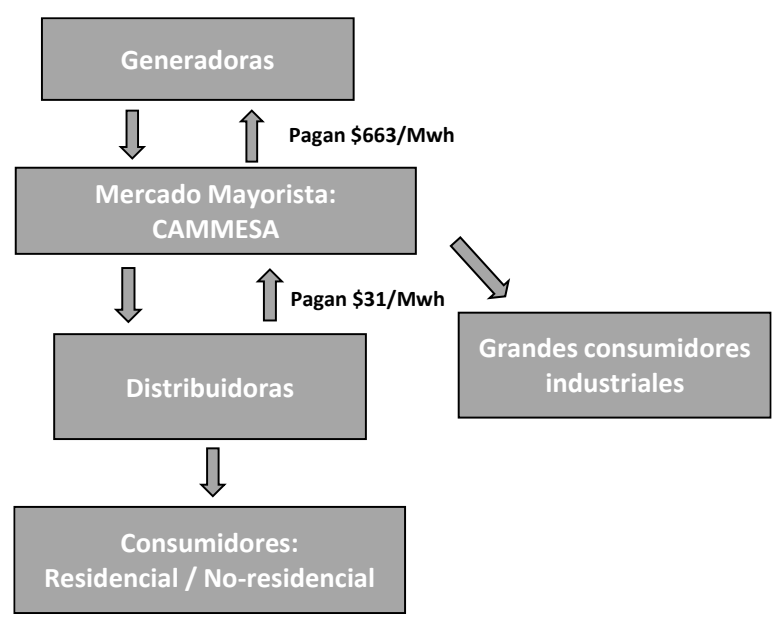

El subsidio es canalizado vía CAMMESA al sector de generación, es decir, sobre el precio de oferta. Luego, las generadoras cobran un precio reducido a las distribuidoras por la provisión de energía eléctrica (precio de demanda). Posteriormente, las distribuidoras asignan los precios al consumidor final (usuarios) utilizando distintos cuadros tarifarios según el nivel de consumo (tramos).

La información sobre el monto de subsidios (transferencias corrientes) que destina el Estado Nacional a CAMMESA se obtiene de los informes presupuestarios de la Asociación Argentina de Presupuesto y Administración Financiera Pública (ASAP).

Por otro lado, los precios monómico y de demanda se obtienen del Informe Anual que realiza CAMMESA.

Por su parte, de la Encuesta Nacional de Gasto de los Hogares (ENGHo) se obtiene, a partir de la variable que reporta el gasto en electricidad por hogar, los consumos de los mismos. Luego, de cada empresa distribuidora se obtienen los cuadros tarifarios pertinentes y que junto con la data recuperada a partir de la ENGHo, se calcula el monto del subsidio por hogar. 


\section{CUADRO A5: :Cómo se compone la tarifa de gas?}

\section{Tarifa $=$ Gas + Transporte + Distribución + Impuestos y Cargos}

Gas: es el valor que corresponde al fluido que se consume. La distribuidora no percibe beneficio sobre el mismo, ya que éste se pasa íntegramente al productor de hidrocarburos (generación).

Transporte: es el valor del servicio que cobran las transportistas (Transportadora de Gas del Sur y del Norte) para llevar el gas desde la boca de pozo (en cada cuenca productora) hasta las zonas de concesión de cada distribuidora. La distribuidora no percibe beneficio sobre el mismo, ya que el valor se pasa íntegramente al transportista.

Distribución: es el valor del servicio de distribución que reciben las empresas para brindar el servicio de distribución del gas.

Impuestos: son los tributos que han de pagarse al Estado.

Cargos: son los cargos específicos (como el subsidio patagónico o los Fondos Fiduciarios) que establece la autoridad regulatoria, para ser utilizados con distintos fines. En este caso la distribuidora (Metro GAS), actúa como agente de percepción y no percibe beneficio económico sobre el mismo.

\section{CUADRO A6: Cálculo del subsidio de gas de red}

Las distribuidoras poseen tres cuadros tarifarios diversos, en base al ahorro respecto a igual bimestre del año anterior: a) Consumo con ahorro de más del 20\%, b) Consumo con ahorro entre el $5 \%$ y el $20 \%$, y c) Consumo con ahorro menor al $5 \%$.

Dado que no existe información fidedigna acerca de cómo identificar el patrón de ahorro en gas de la población, se asume un criterio el cual divide de manera aleatoria a los hogares dentro de los tres tipos de patrones, asumiendo que la distribución de los mismos es 1/3 en cada caso.

A su vez, se utilizan los cuadros tarifarios para cada provincia, pertinentemente. Los mismos corresponden a los últimos disponibles. 